\title{
Do Investor Sophistication and Trading Experience Eliminate Behavioral Biases in Financial Markets? ${ }^{\star}$
}

\author{
LEI FENG ${ }^{1}$ and MARK S. SEASHOLES ${ }^{2}$ \\ ${ }^{1}$ Bear Stearns and Co; ${ }^{2}$ U.C. Berkeley
}

\begin{abstract}
This paper provides an in depth analysis of an investor's reluctance to realize losses and his propensity to realize gains - a behavior known as the disposition effect. Together, sophistication (static differences across investors) and trading experience (evolving behavior of a single investor) eliminate the reluctance to realize losses. However, an asymmetry exists as sophistication and trading experience reduce the propensity to realize gains by $37 \%$ (but fail to eliminate this part of the behavior.) Our research design allows us to follow an individual's behavior from the start of his investing life/career. This ability makes it possible to track the evolution of the disposition effect as it is reduced and/or disappears. Our results are robust to alternative explanations including feedback trading, calendar effects, and frequency of observation.
\end{abstract}

\section{Introduction}

This paper asks: do investor sophistication and trading experience attenuate (or even eliminate) behavioral biases in financial markets? We pay particular attention to the reluctance of investors to realize losses and the propensity to realize gains - a behavior known as the disposition effect. Our work is motivated by the large amount of research concerning the disposition effect over the past two decades. The disposition effect affects individual investors, home buyers, futures traders, professional account managers, experimental laboratory subjects, proprietary stock traders, and financial institutions. ${ }^{1}$ In a very comprehensive study of investment behavior in Finland, Grinblatt and Keloharju (2001) show strong evidence of

$\star$ We thank a national securities firm in China for providing the data used in this study. We are especially grateful to Terry Hendershott who has been instrumental in the development of this paper. In addition, we thank Brad Barber, Sanjiv Das, Kenneth Froot, Alok Kumar, John Nofsinger, Terrance Odean, Jeremy Stein, Andrei Shleifer, and Nancy Wallace for their suggestions. We also thank participants of seminars at Santa Clara University, UC Berkeley, UC Davis, and Wesleyan University. Jack Chu was invaluable in preparing the data for analysis. An earlier version of this paper served as Chapter One of Lei Feng's doctoral dissertation titled "Do Demographics and Experience Change the Disposition Effect?".

1 Some of the best known empirical studies include: Shefrin and Statman (1985); Heisler (1994); Odean (1998); Weber and Camerer (1998); Shapira and Venezia (2001); Grinblatt and Keloharju (2001); Genesove and Mayer (2001); Coval and Shumway (2005); Garvey and Murphy (2004); Locke and Mann (2005); and Locke and Onayev (2005). Appendix A, Panel I gives an overview 
the disposition effect for five investor types: non-financial corporations; financial and insurance institutions; governmental organizations; non-profit institutions; and households. When reviewing published studies in this area, one fact stands out: evidence of the disposition effect is uniformly documented across many investor groups.

Our work is also motivated by views that "the disposition effect is one implication of extending Kahneman and Tversky's (1979) prospect theory to investments" - Odean (1998); and "psychologists and some economists ... claim that investors do not always behave as expected utility maximizers" - Shapira and Venezia (2001). To test which investors may or may not be acting in a manner consistent with prospect theory, existing papers (mentioned above and in Footnote 1) attempt to detect evidence of the disposition effect in a wide variety of investor groups. The large number of published papers stems, in part, from the hypothesis that some groups are more sophisticated/experienced than other groups (i.e., professional money managers vs. retail investors). Researchers want to test if all investors, or only a segment of investors, are prone to the disposition effect. Choosing a sample of investors based on beliefs about the sample's level of sophistication seems like a logical way to proceed. Up until now, there is little evidence of behavior converging toward neoclassical predictions as the disposition effect is economically and statistically significant in each group tested - see Appendix A.

To answer the question posed by the title of this paper, we take a new approach. We investigate behavior at the individual-investor level rather than at the group level as earlier papers do. We study differences in behavior across investors and the evolution of an individual's behavior over time. Throughout this paper we refer to certain static differences across individuals as levels of "sophistication." Such static differences include, for example, an indicator of portfolio diversification at the start of an investor's trading life/career. By definition, we specifically avoid time-varying measures of sophistication. We also construct a simple measure of "trading experience" to study the evolution of an individual's behavior over time. ${ }^{2}$ The contributions of this paper can be categorized in four areas: (i) Sophisticated investors are $67 \%$ less prone to the disposition effect than the average investor in our sample. This result is not about heterogeneity within our sample, rather it stems from a specific test based on an ex-ante measure of investor sophistication. (ii) Trading experience on its own attenuates up to $72 \%$ of the disposition effect, but does not totally eliminate the behavior. (iii) A combination of sophistication and trading experience eliminates the reluctance of investors to realize losses. For example, a sophisticated investor is no longer reluctant to realize losses by the time he initiates his 16th stock position. (iv) There is a large asymmetry in the relationship

of existing empirical studies of the disposition effect. Appendix A, Panel II gives an overview of some recent working papers.

${ }^{2}$ Section 3.2 and Section 4 explain our measures of investor sophistication and trading experience in detail. These measures are sometimes also referred to as "selection" (static preferences) and "treatment" (market experience.) 
between sophistication/experience and the disposition effect. While the reluctance of investors to realize losses is eliminated, there is no amount of investor sophistication/experience that eliminates an investor's propensity to realize gains. This finding is, to our knowledge, new. We also believe that our results regarding trading experience and the disposition effect represent the most interesting contributions of this paper. We therefore turn to reviewing these results in greater detail.

\subsection{CONTRIBUTIONS TO OUR UNDERSTANDING OF THE EFFECTS OF EXPERIENCE}

This paper builds on recent work by List (2003) who studies experience, memorabilia dealers, and memorabilia collectors. We extend his findings in three new dimensions. First, List (2003) studies the interaction of market experience and the endowment effect; we study the interaction of market experience and the disposition effect. ${ }^{3}$ The two behavioral biases are not equivalent therefore it is not $a$ priori obvious if experience will have a similar effect in both situations. In fact, trading experience plays a different role vis-à-vis the disposition effect than it does vis-àvis the endowment effect. For example, trading experience alone does not eliminate the disposition effect. A combination of sophistication and trading experience eliminates investors' reluctance to realize losses, but the same combination only reduces (does not fully eliminate) investors' propensity to realize gains.

The second contribution concerns the markets studied. List (2003) studies two markets (sports memorabilia and collector pins) where goods are not exactly uniform. In one controlled experiment, the author distributes a Kansas City Royals game ticket stub to test subjects. He reports the good is "unique and not typically bought and sold on the sports memorabilia market." The choice of good is by design. Therefore "there was little guidance on the market value/preferences." It is clear that there exist many different types of pro sporting event tickets (dimensions include sport/date/historic event/etc.) Ticket quality adds to the dimensionality of goods in the sports memorabilia market - two tickets from the same game can be of very different quality. A dealer undoubtedly gains experience by seeing many different types of tickets. One might hypothesize that experience helps participants discern quality differences and estimate prices of new, possibly rare, and/or illiquid items. In contrast, our paper studies trading of public company shares (stock) on an electronic limit order book exchange. Investors do not differentiate stocks based on share certificate numbers - all shares of the same class from the same firm are of equal value in their eyes. This feature of financial markets is different from baseball card markets where two cards of the same player from the same year may have different values due to hard-to-discern quality differences. Experience does not help an investor study the actual share certificates. However, experience is likely to help an investor resist urges that lead to money-losing trades. Resisting such

\footnotetext{
3 List (2003) writes "Thaler (1980) coined the term endowment effect, which implies that a good's value increases once it becomes part of an individual's endowment."
} 
an urge can be important when considering the disposition effect since individual investors tend to be poor at deciding when to sell and when to hold a stock. Using US data, Odean (1998) shows stocks investors sell tend to keep going up and stocks they hold tend to keep going down. Chen, Kim, Nofsinger, and Rui (2004) show a similar pattern in China.

The third contribution concerns research design and observation frequency. List (2003) uses self-reported values of trading experience, though he does re-visit one market a year after making his original measurements. By contrast, we "observe" each investor's decision to trade or not on a daily basis. In our research design, we observe investors from the start of their trading lives/careers. We can measure the reluctance to realize losses at the time of an investor's 1 st, $2 \mathrm{nd}, 3 \mathrm{rd}$... transaction. In this way, we are able to draw experience curves for specific individuals (or groups of similar individuals.) These experience curves allow us to track the time-path evolution of a bias as it is reduced and/or disappears.

Our paper proceeds as follows. Section 2 overviews our methodology and data. Section 3 presents results related to investor sophistication. Section 4 examines investor experience and the evolution of behavior over time. At the end of Section 4, we jointly estimate the effect of sophistication and trading experience on an individual's reluctance to realize losses and propensity to realize gains. Section 5 explores an number of alternative explanations for our findings. Section 6 concludes.

\section{Methodology and Data}

\subsection{METHODOLOGY}

In order quantify the magnitude of the disposition effect, we follow a methodology related to the Logit regressions used in Grinblatt and Keloharju (2001). Our paper and Grinblatt and Keloharju (2001) both regress a holding indicator at the stock position level $(1=$ Sell; $0=$ Hold $)$ on independent variables. Of particular interest in both papers are independent variables related to trading losses (e.g., indicators such as $1=$ Stock is selling for a loss; $0=$ Otherwise.) The coefficient on the trading loss indicator indicates whether investors are reluctant to sell at a loss. ${ }^{4}$

We depart from the traditional Logit methodology and use survival analysis. This method offers three main advantages: (i) A statistical model (baseline) of how long stocks are typically held in a portfolio. In our paper, the statistical model indicates a non-constant probability of selling over time; (ii) The use of holdings/market data on days when an investor does not buy or sell a stock; and (iii) An easy way to interpret the probability of selling, as well as an easy way to interpret changes

\footnotetext{
4 See Grinblatt and Keloharju (2001) Table 1, Panel C. The authors use two trading loss indicators. The first takes a value of one if the stock is sold (or is trading at) an extreme loss of $-30 \%$ to $-100 \%$. The second takes a value of one if the stock is sold (or is trading at) a moderate loss of $0 \%$ to $-30 \%$.
} 
to this probability due to a change in an independent variable (e.g., conditional on a change to the trading loss indicator. $)^{5}$

Both the Logit methodology and survival analysis allow the econometrician to test for the disposition effect while at the same time controlling for factors that might be correlated with the propensity to trade. These control variables become very important when investigating investor behavior at the individual level. Even today (as can be seen in Appendix A, Panel II), the most popular method of testing for the disposition effect is based on measuring various ratios of sales for gains and sales for losses. These measures - based on work by Odean (1998) - are typically referred to as "PGR" and "PLR". It turns out the measures work for studying the disposition effect on average, but do not perform well at the individual account level. In particular, the measures vary with exactly the demographic variables one might think are related to the disposition effect. For example, an econometrician might hypothesize that investors with more stocks in their portfolios are less prone to the disposition effect than investors with just a few stocks in their portfolios. After all, the number of stocks is a measure of sophistication as it shows the desire to diversify. But the number of stocks in an investor's portfolio is mechanically linked to the PGR and PLR measures. Appendix D provides a number of examples. The PGR and PLR measures have an additional problem when used at the individual account level. Many individuals only sell stocks for gains or only sell stocks for losses. Thus, the PGR or PLR measures are by no means smooth, continuous variables when used in cross-sectional regressions. There is severe bunching of the measures and their difference, $P G R-P L R$, is frequently equal to positive one, zero, or negative one. ${ }^{6}$

As mentioned above, readers can think of our survival analysis as a statistical model that describes how long investors in our sample typically hold a stock position before selling. Figure 1 graphs the baseline survival function of stock holdings from our sample data (the data are described below in Section 2.2). From the graph we see that less than $10 \%$ of all stock positions are held for more than 50 days. Included in the figure is a fitted exponential for comparison. It is clear that the empirical survival function initially declines more quickly than the exponential. An exponential survival function implies a constant probability of selling a stock over time. We allow for non-constant selling probabilities which is different from assumptions (explicit or implicit) in other studies of the disposition effect.

For each day $t$ after a stock is bought, we calculate the conditional probability of the stock being sold (i.e., conditional on the stock surviving in the portfolio up until day $\mathrm{t}-1$.) This conditional probability on any date $t$ is called the baseline

\footnotetext{
5 Appendix B reviews math and the associated estimation procedures related to survival analysis. References are also provided. Appendix C provides a stylized example showing how survival analysis benefits testing for the disposition effect. Most existing papers only consider an investors' portfolio on sales dates. Appendix $\mathrm{C}$ shows the value of examining holdings/market data on days between a stock's purchase date and sales date.

6 Our data indicate bunching may affect up to $30 \%$ of all accounts.
} 


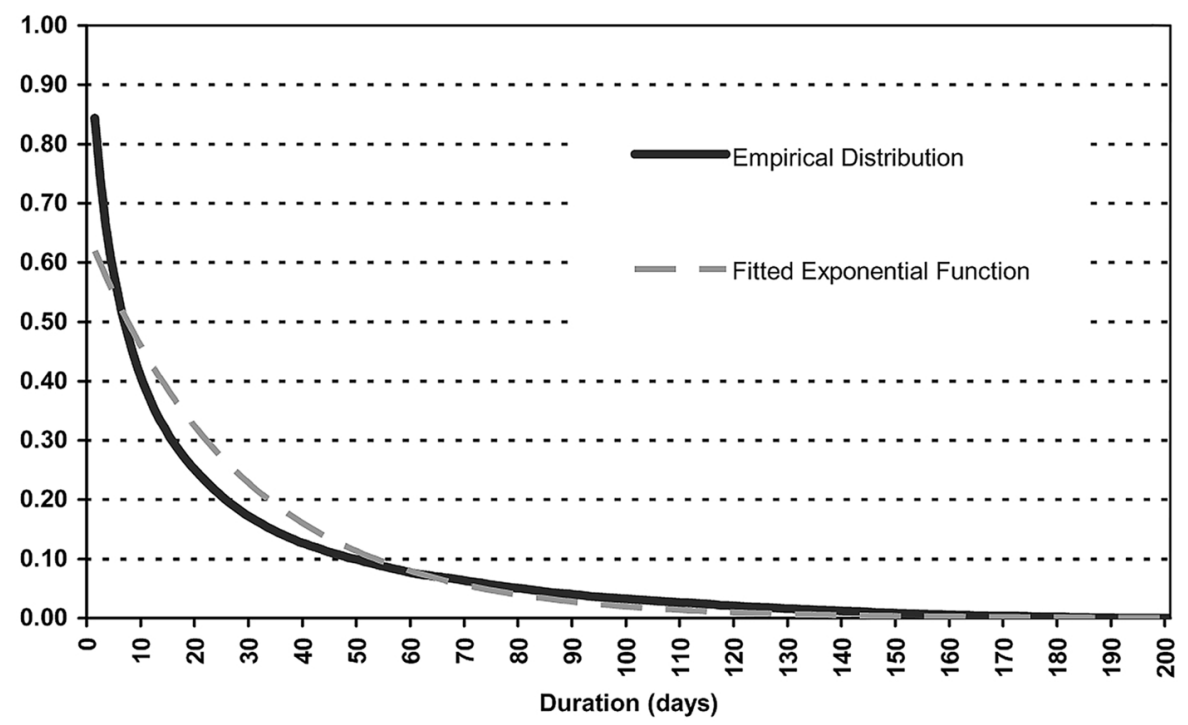

Figure 1. Baseline survival function. The graph shows the empirical survival function of stock holdings in our sample. In this paper, a position failure time is the number of days between when a stock position is initiated and when it is first sold. The survival function is equal to one minus the cumulative distribution function of the position failure time. The graph also shows a fitted exponential for comparison. Data are from January 1999 to December 2000 and are provided by a large brokerage house in the People's Republic of China.

"hazard rate" and can be calculated directly from the baseline survival function shown in Figure 1. There is no set functional form for the baseline hazard function and nonparametric approaches are possible. We use a Weibull hazard function in order to capture the non-constant (i.e., non-exponential) change in the baseline survival function. The Weibull function can be described succinctly with parameter $p$ and a constant of integration $\lambda$ :

$$
\begin{aligned}
& f(t)=p \lambda t^{p-1} \exp \left(-\lambda t^{p}\right) \\
& S(t)=\exp \left(-\lambda t^{p}\right) \\
& h(t)=p \lambda t^{p-1} .
\end{aligned}
$$

Similar to Logit regressions, we regress a sell/hold indicator variable on the baseline hazard function and other independent variables called "covariates." Right-hand side variables can either be constant (called "fixed covariates") or not (called "time-varying covariates"). The right-hand side variables can represent investor-specific characteristics, stock-specific characteristics, or general market characteristics. In addition, stock-specific and investor-specific variables can be interacted - which we do extensively in this paper. Regression coefficients ( $\beta$ 's and $\gamma$ 's) are estimated using maximum likelihood:

$$
h\left(t, p, X, Z_{t}\right)=p \lambda t^{p-1} \exp \left(X \beta+Z_{t} \gamma+\varepsilon_{t}\right) .
$$


Rather than reporting regression coefficients ( $\beta$ 's and $\gamma$ 's) from Equation (2), we follow convention and report hazard ratios. The hazard ratio of a coefficient $\gamma$ is equal to $e^{\gamma}$. We can think of a coefficient's hazard ratio as reporting a change in the hazard rate when the independent variable changes from zero to one. Thus, interpreting the economic significance of dummy (indicator) variables becomes particularly easy:

$$
\begin{aligned}
\operatorname{hazard} \operatorname{ratio}(\gamma) & =\frac{h\left(t, p, X, Z_{t}=1\right)}{h\left(t, p, X, Z_{t}=0\right)} \\
& =\exp (\gamma)
\end{aligned}
$$

Survival analysis of stock market decisions can involve a lot of data. For example, studying 1,000 investors who hold an average of four stocks for a two-year period (250 trading days per year) requires 2,000,000 observations. But the analysis offers great flexibility. Researchers can investigate continuous and discrete hazard functions. The discrete distributions can be parametric or nonparametric. Covariates (right-hand side variables, $X$ and $Z_{t}$ ) can be used to control for a large number of effects. Estimation is by maximum likelihood. Statistical inference is straightforward and corrections can be made for clustering of observations. Section 5.5 checks that using lower frequency data does not qualitatively change our results.

We consider subsequent buys (those after the initial buy) to be holds since the investor does, in fact, continue to hold the stock. We estimate the time until the first failure. Our approach simplifies the analysis and makes economic sense if one believes some investors tend to break up trades. In other words, we care about the conditions that initiate the first sale. In order to make our results as comparable as possible to existing studies, we consider completed round-trip transactions. Future research need not do this. Positions that are not closed-out by the end of the sample (observation) period may still be included in the analysis.

\subsection{DATA}

We use account-level data from a national brokerage firm in the People's Republic of China ("PRC"). The data contain information on transactions and stock holdings. Our data are comprised of 1,511 investors (accounts). In order to accurately measure the evolution of investor behavior, all accounts studied in this paper are opened on or after January 1, 1999, the start of our sample period. Since securities laws in the PRC only allow an investor to open one account, our methodology allows us to "observe" an individual's trading decisions from the outset of his or her investing life/career. ${ }^{7}$ A single record includes an individual's account number,

\footnotetext{
7 Previous versions of this paper (for example from June 2004) reported results based on investors from a single brokerage branch office. The current version uses data from two brokerage branch offices. Together, the two branch offices have over 2,900 accounts of which 1,511 were opened on or after January 1, 1999. Comparison of results between this draft and the earlier draft shows very
} 
date, stock ticker, buy/sell indicator, transaction price, number of shares, and share balance after the transaction. In this study, buys and sells are aggregated on a daily basis for each account and each listed stock. The dataset contains 529,425 account/stock/date observations.

Table I gives some overview statistics of the data used in this study. The average age of an investor in our sample is 34.71 years old as of the January 1999 which is the beginning of our sample period. Investors have a median of five trading rights where an example of a trading right is the ability to place telephone trades. Trading rights are discussed more thoroughly in Section 3.2. The median account has RMB 47,177 which is equal to USD 5,897 at an 8:1 exchange rate. The average account has approximately USD 30,000 indicating some fairly wealthy individuals in our sample. Our sample contains $51.42 \%$ males and $48.58 \%$ females. ${ }^{8}$

Table I shows our dataset contains 21,631 positions (round-trip transactions.) This averages to 14.32 positions per investor with the median investor taking 7 positions during our two year sample period. Positions are held for an average of 24.48 days which gives us the over half million "observations" of investor/stock/date holdings. In Section 5.5 we switch to weekly data to ensure statistical inference is not affected by the seemingly large number of observations.

As mentioned above, brokerage rules in the PRC allow only one account per individual. Therefore, we have the complete stock trades and holdings for the individual investors in our study. Unlike studies that use US data, individuals in the PRC do not have multiple brokerage accounts, nor do they have alternative equity holdings (401 Ks, etc.). There are also no capital gains taxes in the PRC. Therefore, there are no confounding effects from tax-loss selling when studying the disposition effect - see Shapira and Venezia (2001) for a similar situation in Israel. Finally, the MSCI China Index does not have a prominent trend over our sample period. The average monthly return is $-0.34 \%$ from the January 1999 to December 2000. The MSCI Emerging Markets Index has a 1.20\% average monthly return during this same time period. The China index is more volatile than the MSCI Emerging Markets Index (14\% vs. $6 \%$ monthly volatility over our sample period.) $)^{9}$

Positions. We sort our data by account number, then stock ticker, and finally by date. Like Shapira and Venezia (2001), we define a position as starting when an investor first purchases a given stock and ending when the share balance goes to zero. This definition allows positions to be "built up" through multiple purchases and "sold off" through multiple sales. The majority of positions, $69.15 \%$, consist

similar results. Thus, the second brokerage branch office provides out-of-sample confirmation of earlier results.

8 An overview of PRC investors can be found in Chen, Kim, Nofsinger, and Rui (2004) who also point out the high fraction of female participation in the market relative to female participation in the United States.

9 The short sample period undoubtedly contributes to differences between the average return of the MSCI China Index and the MSCI Emerging Markets Index. 
Table I. Overview statistics

This table reports summary statistics of data used in this study. The primary data set includes individual trades between January 1999 and December 2000 placed at a large brokerage house in the People's Republic of China (PRC). The Chinese currency is called "Renminbi" and denoted with RMB. We study accounts opened on or after January 1, 1999. In this study, buys and sells are aggregated on a daily basis for each account and each listed stock.

\begin{tabular}{|c|c|c|c|c|}
\hline & \multicolumn{4}{|c|}{ Mean } \\
\hline Number of investors (accounts) & \multicolumn{4}{|c|}{1,511} \\
\hline Percentage of male investors & \multicolumn{4}{|c|}{$51.42 \%$} \\
\hline Number of account-stock-days & \multicolumn{4}{|c|}{529,425} \\
\hline Number of positions & \multicolumn{4}{|c|}{21,631} \\
\hline Average position holding time (days) & \multicolumn{4}{|c|}{24.48} \\
\hline Average time to first sale (days) & \multicolumn{4}{|c|}{19.10} \\
\hline & Mean & 25th-tile & 50th-tile & 75th-tile \\
\hline Average investor age (years) & 34.71 & 26.18 & 31.15 & 40.53 \\
\hline Number of trading rights & 5.37 & 4 & 5 & 6 \\
\hline Average balance (RMB) & 244,995 & 15,968 & 47,177 & 167,973 \\
\hline Total positions taken (per investor) & 14.32 & 3 & 7 & 17 \\
\hline
\end{tabular}

of a single purchase and a single sale (similar to numbers reported in the United States.) Table II gives an overview of the number of buys and sales involved with the positions in our sample. Our unit of analysis is investor-stock position-day. ${ }^{10}$ Table I shows the average holding time is 24.48 days and the time to first sale is 19.10 days. For positions that consist of one sale, the holding time equals the time to first sale.

Gains and Losses. For each investor-stock position-date in our sample, we make two types of comparisons. The first comparison involves actual sales of stock. If the investor sells a stock, we compare the selling price to the original purchase price or "reference price." The share-weighted average purchase price is used as the reference price in this paper. ${ }^{11}$ The second comparison involves holdings. If the investor does not sell a stock (i.e., he holds the position) we determine if the stock is trading at a gain or a loss. If a stock's daily low is above its reference (purchase)

\footnotetext{
10 We do not have intraday price data. Therefore, daily portfolios are the highest frequency we can examine.

11 We can calculate the reference price in a number of different ways: first purchase price, highest purchase price, average purchase price, and most recent purchase price. To ensure the robustness of the results, we test all possible measures and the results remain essentially unchanged. For positions that consist of a single purchase, all these measures are equivalent.
} 
Table II. Position buys and sales

This table shows the number of buys and number of sales used to "build up" and "sell off" each of the 21,631 positions in our sample. A position starts when an investor buys a stock and ends when the balance (in shares) goes to zero. Stock positions may be built-up through multiple purchases or sold-off through multiple sales. The fraction of the total 21,631 positions is shown below each number in italics.

\begin{tabular}{ccccccc}
\hline \multirow{2}{*}{$\begin{array}{c}\text { Number of buys used to } \\
\text { build up a position }\end{array}$} & \multicolumn{6}{c}{ Number of sales used when selling-off position } \\
\cline { 2 - 7 } & 1 & 2 & 3 & 4 & 5 & More \\
\hline 1 & 14,958 & 1,574 & 241 & 59 & 22 & 18 \\
& $69.15 \%$ & $7.28 \%$ & $1.11 \%$ & $0.27 \%$ & $0.10 \%$ & $0.08 \%$ \\
2 & 1,890 & 783 & 229 & 64 & 29 & 16 \\
& $8.74 \%$ & $3.62 \%$ & $1.06 \%$ & $0.30 \%$ & $0.13 \%$ & $0.07 \%$ \\
3 & 377 & 320 & 142 & 55 & 15 & 20 \\
& $1.74 \%$ & $1.48 \%$ & $0.66 \%$ & $0.25 \%$ & $0.07 \%$ & $0.09 \%$ \\
4 & 90 & 97 & 75 & 51 & 22 & 17 \\
& $0.42 \%$ & $0.45 \%$ & $0.35 \%$ & $0.24 \%$ & $0.10 \%$ & $0.08 \%$ \\
5 & 33 & 49 & 31 & 29 & 14 & 26 \\
& $0.15 \%$ & $0.23 \%$ & $0.14 \%$ & $0.13 \%$ & $0.06 \%$ & $0.12 \%$ \\
More & 33 & 36 & 43 & 38 & 79 & 196 \\
& $0.15 \%$ & $0.17 \%$ & $0.20 \%$ & $0.17 \%$ & $0.18 \%$ & $0.46 \%$ \\
\hline
\end{tabular}

price, it is counted as a "paper gain" (in other words, the investor could have sold at a gain at any time during the day). If a remaining stock's daily high is below its original purchase price, it is counted as a "paper loss" (the investor could only have sold for a loss that day).

We define two indicator variables that are key to our results. The first indicator variable is called the "Trading Loss Indicator" or "TLI". The variable takes a value of one if the stock is sold for a loss or the stock is trading at a paper loss. The TLI takes a value of zero otherwise. Our second indicator variable is called the "Trading Gain Indicator" or "TGI". The variable takes a value of one if the stock is sold for a gain or the stock is trading at a paper gain. The TGI takes a value of zero otherwise. Both the TLI and TGI vary over time - a stock might be trading at a loss one day but not the next. The TLI and TGI cannot both be included in any regression with a constant since (except in rare instances) stocks are either trading at a loss or a gain.

The key part of our analysis revolves around hazard ratios associated with the Trading Loss Indicator (TLI) and Trading Gain Indicator (TGI). A hazard ratio less than one for the TLI indicates investors are less likely to sell a stock at a loss than the baseline hazard function indicates. A hazard ratio greater than one for the TGI indicates investors are more likely to sell a stock at a gain than the baseline hazard function indicates. 


\section{Investor Sophistication and the Disposition Effect}

This section contains three parts. We first show that investors in our sample exhibit the disposition effect on average. We then show that sophistication is correlated with the disposition effect in a predictable manner. We end by showing that sophistication attenuates, but does not fully eliminate, the disposition effect.

\subsection{TESTS FOR THE DISPOSITION EFFECT (ON AVERAGE)}

We test if investors in our sample are reluctant to sell losers on average. To carry out the test, we estimate the hazard model shown in Equation (2). The left-hand side variable is an indicator that equals zero for every day an investor holds a stock position and one if he sells the stock. The only right-hand side variable at this point is the "Trading Loss Indicator (TLI)" described at the end of Section 2. As with past studies, we pool all investors together and estimate a single hazard ratio. We thereby report an average effect across investors.

In Table III, Regression 1 we report the hazard ratio on the Trading Loss Indicator (TLI). A hazard ratio greater than one measures an increase in the conditional probability of a sale due to a change in the covariate. A hazard ratio less of than one measures a decrease in the probability of a sale due to a change in the covariate. The extremely low value of the TLI hazard ratio is evidence that the average investor is prone to the disposition effect. We see that the hazard rate of a sale decreases by 0.3679 (where $0.6321-1.0000=-0.3679$ ) if a stock is trading below its reference price. The hazard ratio of the TLI (0.6321) is significantly lower than one. ${ }^{12}$ Note that statistical significance reported in our paper is based on robust standard errors that allow for clustering by stock position - Section 5.5 explores the benefits of allowing clustering in more detail.

We next test if investors in our sample have a propensity to sell winners (on average.) Our results are shown in Table III, Regression 2. The hazard ratio associated with the Trading Gain Indicator (TGI) is 4.3842 and indicates a significantly increased probability of selling (relative to the baseline) if a stock is trading above its reference price. In other words, the conditional probability of a sale increases when a stock is trading for a gain. ${ }^{13}$

Readers who have trouble interpreting a conditional increase of 3.38x (calculated from the hazard ratio: $4.3842-1.0000=3.3842$ ) can consider the stylized example given in Appendix C. Suppose the hazard rate for all investors is constant each day at $5.00 \%$. Appendix $\mathrm{C}$ describes four investors who happen to hold positions for exactly twenty days. Consider Investor A in the example: the investor sells the first possible moment the stock trades for a gain. In other words, Investor A

\footnotetext{
12 Regressions with a trading loss indicator can be most easily compared with Grinblatt and Keloharju (2001) since they also include loss indicators. Households in Finland are $21 \%$ less likely to sell at a moderate trading loss and $32 \%$ less likely to sell at an extreme trading loss.

13 For the most part, stocks are effectively either trading for a gain or a loss. Therefore, we test TLI and TGI separately since we also fit a constant in the regression to estimate the parameter $p$.
} 
Table III. Test for the disposition effect (on average)

This table presents hazard ratios associated with the average individual's decision to sell/hold stocks at a loss/gain. The left-hand side variable takes a value of zero every day the individual holds a stock, and the left-hand side variable takes a value of one every day s/he sells a stock. In Regression 1, the independent variable is an indicator that takes a value of one every day a stock is trading at a loss (relative to the purchase price) and zero otherwise. In Regression 2, the independent variable is an indicator that takes a value of one every day a stock is trading at a gain (relative to the purchase price) and zero otherwise. We use a Weibull distribution with parameter " $p$ " to parameterize the hazard function. A parameter value of $\mathrm{p}=1$ indicates an exponential hazard rate. A parameter value of $p<1$ indicates a decreased hazard rate over time. Data are from January 1999 to December 2000 and are provided by a large brokerage house in the People's Republic of China. $Z$-stats are based on robust standard errors that allow for clustering by position (a single position is taken by a single investor in a particular stock-please see text for further details.) $Z$-stats are shown in parenthesis below the hazard ratios.

\begin{tabular}{lcc}
\hline & Reg 1 & Reg 2 \\
\hline Trading Loss Indicator or "TLI" & 0.6321 & \\
(Z-stat) & $(-27.3)$ & \\
Trading Gain Indicator or "TGI" & & 4.3842 \\
(Z-stat) & & $(95.4)$ \\
p-parameter & 0.7626 & 0.7280 \\
(std. err) & $(0.0034)$ & $(0.0035)$ \\
\hline
\end{tabular}

sells the stock $100 \%$ of the time it trades for a gain, even though the conditional probability of a sale is the $5.00 \%$ constant hazard rate. If most investors in our sample acted like Investor A, the hazard ratio associated with the TGI would be near 20! In this way, a hazard ratio of 4.3842 appears well within the bounds of reasonableness.

Our initial results confirm the existence of the disposition effect in a yet another sample - PRC retail investors. We now examine the relationship between investor sophistication and the disposition effect. Alternative explanations and robustness checks (such as feedback trading and calendar effects) are considered in Section 5.

\subsection{SOPHISTICATION AND THE DISPOSITION EFFECT (AT THE INVESTOR-LEVEL)}

We test if investor sophistication attenuates, or even eliminates, the disposition effect. As discussed in the Introduction and Appendix A, existing studies use samples of different investors types - such as CBOT traders - to investigate the relationship between sophistication and behavioral biases. We investigate whether 
more sophisticated traders are less prone to the disposition effect. Unlike most earlier studies, we test for differences within our sample. ${ }^{14}$

To carry out our tests, we: (i) Include demographic variables; and (ii) Interact the demographic variables with the Trading Loss Indicator (TLI) and Trading Gain Indicator (TGI). The interaction terms are of key interest since they directly answer the question of whether changes in demographic variables are correlated with changes in an investor's propensity to avoid losses and realize gains. The demographic variables by themselves act as controls because members of one demographic group may have shorter average holding times than other individuals. The inclusion of control variables cannot be emphasized enough. A first-time reader of this paper invariably questions whether investors of type $\mathrm{X}$ are simply more likely to sell at a gain (or sell at a loss). To address such questions we also report hazard ratios associated with the control variables. In short, survival analysis gives us the ability to control for different behavior while, at the same time, we are able to test for cross-sectional differences in the disposition effect. The ability to include control variables sets our methodology apart from most existing measures in cross-sectional studies. ${ }^{15}$

We need proxy variables for investor sophistication. Finding such variables is not easy and we worry that variables - such as current value of stock holdings, current number of stocks in a portfolio, and transaction frequency - are co-determined with the decision to buy or sell. Therefore, we choose the number of trading rights and an indicator variable of initial portfolio diversification. We also include two demographic variables that are likely to be related to sophistication (the variables are gender and age). Our goal is to choose variables are not directly linked to trading behavior during our sample period. In order to study investor sophistication, we choose variables that are known at the start of our sample period. In Section 5 we test alternative regressions.

Trading Rights. In the PRC, an investor has different ways to place orders. He can place a trade through his branch office using paper tickets, through automated computer terminals, via telephone, or via internet links. The investor must apply for the "right" to trade and receive authorization for each method before he is allowed to use it. The account information data contain a list of authorized "rights" at the time the investor opened the account. We use the total number of "rights" authorized for each account as a proxy for investor sophistication. We hypothesize that sophisticated investors are generally inclined to use more methods to trade. They apply for, and are granted, more rights at the time they open their accounts.

Indicator of Initial Diversification. We look at the number of stocks in an investor's portfolio on the first day the investor trades. We hypothesize that more sophisticated investors tend to diversify their portfolios right from the start of their

\footnotetext{
14 Two obvious exceptions are: Shapira and Venezia (2001); Grinblatt and Keloharju (2001).

15 See Appendix D.
} 
trading lives/careers. Therefore, we construct a diversification indicator variable that equals one if an investor begins his or her investing career by purchasing two or more stocks. The diversification indicator variable equals zero if the investor initially purchases a single stock.

Gender. Previous research in both psychology and empirical behavioral finance demonstrates gender differences in investment behavior. Barber and Odean (2001) shows that men trade $45 \%$ more than women, and that trading costs reduce men's net returns by 2.65 percentage points a year, as opposed to 1.72 percentage points for women. The authors attribute their findings to men being more overconfident than women, (not necessarily to investor sophistication). This result may apply to US investors only. As Table I shows, the fraction of female investors in the PRC is much higher than the US fraction of $20 \%$.

Age. Ang and Maddaloni (2005) and Goyal (2004) demonstrate that age affects individual investment decisions. We expect investors in different age groups to vary in the disposition effect. We hypothesize that there are competing age effects in the PRC. One effect is that sophistication increases with age. The other effect has to do with what economic regime was in place during an investor's formative years. We hypothesize that older investors, who grew up during times of highly centralized planning, are not as sophisticated as those who grew up during post-1980 switch to a more open economy. Clearly this view of the age-sophistication relationship is specific to transition economies such as the PRC. For readers who have traveled to the PRC or conducted research in the country, it is not hard to rationalize referring to the young 25 to 35 year old business men and business women as the most sophisticated investor age group. We create age bracket indicators: $\leq 25,(25,35]$, $(35,45],(45,55]$, and $>55$. We expect investors in the $(25,35]$ bracket to be less prone to the disposition effect while we expect investors in the $>55$ bracket to be the most prone.

\subsubsection{Investor Sophistication and Losses}

Table IVa, Regressions 1, 2, and 3 test the investor sophistication covariates separately. Regression 4 tests all covariates together. We focus on Regression 4 and see that additional trading rights increase the propensity to sell loser stocks. The hazard ratio associated with trading rights and selling for a loss is 1.0651 with a $5.2 \mathrm{Z}$-stat. Note that, increasing one's propensity to sell losers is the same as decreasing one's reluctance to realize losses. We next see that the initial diversification indicator is correlated with an increased propensity to sell losers (1.1942 hazard ratio with a $4.7 \mathrm{Z}$-stat.) Finally, note that male investors are much more likely to sell losers than female investors (1.3652 hazard ratio).

The hazard ratios for the age bracket indicators are also shown in Table IVa. Not shown are hazard ratios for the $<25$ age bracket since this value is part of the baseline TLI. To read the results consider the less-than-twenty-five year 
Table IVa. Trading losses, sophistication, and investor demographics

This table presents hazard ratios associated with an individual's decision to sell/hold stocks. The left-hand side variable takes a value of zero every day the individual holds a stock, and one every day s/he sells a stock. Demographic variables are fixed over time, but vary across individuals. The demographic variables (described in more detail in the text) include an individual's number of trading rights, a measure of initial portfolio diversification, a gender indicator, and age-bracket indicators. We interact each demographic variable with the Trading Loss Indicator (TLI) in order to measure cross-sectional differences in investors' propensities to hold losers. The Trading Loss Indicator takes a value of one every day a stock is trading below its purchase price, and zero otherwise. Demographic variables are also used as control variables. We use a Weibull distribution with parameter " $p$ " to parameterize the hazard function. Data are from January 1999 to December 2000. $Z$-stats are based on robust standard errors that allow for clustering by position (a single position is taken by a single investor in a particular stock-please see text for further details.) $Z$-stats and standard errors are shown in parenthesis below the hazard ratios.

\begin{tabular}{|c|c|c|c|c|}
\hline & Reg 1 & Reg 2 & Reg 3 & $\operatorname{Reg} 4$ \\
\hline \multicolumn{5}{|l|}{ Disposition Effect Variables } \\
\hline Trading Loss Indicator or "TLI" & 0.4685 & 0.6067 & 0.5300 & 0.3638 \\
\hline (Z-stat) & $(-10.9)$ & $(-26.5)$ & $(-26.0)$ & $(-12.6)$ \\
\hline Number of Trading Rights $\times$ TLI & 1.0555 & & & 1.0651 \\
\hline (Z-stat) & $(4.5)$ & & & $(5.2)$ \\
\hline Diversification Dummy $\times$ TLI & & 1.1681 & & 1.1942 \\
\hline (Z-stat) & & $(4.1)$ & & $(4.7)$ \\
\hline Gender $(0=\mathrm{F}, 1=\mathrm{M}) \times$ TLI & & & 1.3628 & 1.3652 \\
\hline (Z-stat) & & & $(9.8)$ & $(9.7)$ \\
\hline Age $\in(25,35] \times$ TLI & & & & 1.0821 \\
\hline (std. err) & & & & $(0.05)$ \\
\hline Age $\in(35,45] \times$ TLI & & & & 0.8299 \\
\hline (std. err) & & & & $(0.05)$ \\
\hline Age $\in(45,55] \times$ TLI & & & & 0.9168 \\
\hline (std. err) & & & & $(0.06)$ \\
\hline Age $>55 \times$ TLI & & & & 0.8653 \\
\hline (std. err) & & & & $(0.06)$ \\
\hline \multicolumn{5}{|l|}{ Control Variables } \\
\hline Number of Trading Rights & 1.0187 & & & 1.0179 \\
\hline (Z-stat) & $(2.8)$ & & & $(2.7)$ \\
\hline Diversification Dummy & & 1.2207 & & 1.2199 \\
\hline (Z-stat) & & $(9.6)$ & & $(9.5)$ \\
\hline Gender $(0=\mathrm{F}, 1=\mathrm{M})$ & & & 1.0734 & 1.0750 \\
\hline (Z-stat) & & & $(4.1)$ & $(4.1)$ \\
\hline Age $\in(25,35]$ & & & & 1.0757 \\
\hline (std. err) & & & & $(0.03)$ \\
\hline Age $\in(35,45]$ & & & & 1.1551 \\
\hline (std. err) & & & & $(0.03)$ \\
\hline Age $\in(45,55]$ & & & & 1.1590 \\
\hline (std. err) & & & & $(0.04)$ \\
\hline Age $>55$ & & & & 1.0235 \\
\hline (std. err) & & & & $(0.04)$ \\
\hline \multicolumn{5}{|l|}{ Parameters } \\
\hline$p$-parameter & 0.7638 & 0.7656 & 0.7659 & 0.7717 \\
\hline (std. err) & $(0.0034)$ & $(0.0034)$ & $(0.0034)$ & $(0.0035)$ \\
\hline
\end{tabular}


Table IVb. Trading gains, sophistication, and investor demographics

This table presents hazard ratios associated with an individual's decision to sell/hold stocks. The left-hand side variable takes a value of zero every day the individual holds a stock, and one every day s/he sells a stock. Demographic variables are fixed over time, but vary across individuals. The demographic variables (described in more detail in the text) include an individual's number of trading rights, a measure of initial portfolio diversification, a gender indicator, and age-bracket indicators. We interact each demographic variable with the Trading Gain Indicator (TGI) in order to measure cross-sectional differences in investors' propensities to sell winners. The Trading Gain Indicator takes a value of one every day a stock is trading above its purchase price, and zero otherwise. Demographic variables are also used as control variables. We use a Weibull distribution with parameter " $p$ " to parameterize the hazard function. Data are from January 1999 to December 2000. $Z$-stats are based on robust standard errors that allow for clustering by position (a single position is taken by a single investor in a particular stock-please see text for further details.) $Z$-stats and standard errors are shown in parenthesis below the hazard ratios.

\begin{tabular}{|c|c|c|c|c|}
\hline & $\operatorname{Reg} 1$ & $\operatorname{Reg} 2$ & Reg 3 & $\operatorname{Reg} 4$ \\
\hline \multicolumn{5}{|l|}{ Disposition Effect Variables } \\
\hline Trading Gain Indicator or "TGI" & 5.6382 & 4.5526 & 5.1781 & 7.0095 \\
\hline (Z-stat) & $(26.0)$ & $(85.3)$ & $(70.5)$ & $(25.1)$ \\
\hline Number of Trading Rights $\times$ TGI & 0.9555 & & & 0.9506 \\
\hline (Z-stat) & $(-3.9)$ & & & $(-4.3)$ \\
\hline Diversification Dummy $\times$ TGI & & 0.8565 & & 0.8432 \\
\hline (Z-stat) & & $(-4.2)$ & & $(-4.6)$ \\
\hline Gender $(0=\mathrm{F}, 1=\mathrm{M}) \times$ TGI & & & 0.7422 & 0.7418 \\
\hline (Z-stat) & & & $(-9.6)$ & $(-9.5)$ \\
\hline Age $\in(25,35] \times$ TGI & & & & 0.9287 \\
\hline (std. err) & & & & $(0.04)$ \\
\hline Age $\in(35,45] \times$ TGI & & & & 1.1555 \\
\hline (std. err) & & & & $(0.06)$ \\
\hline Age $\in(45,55] \times$ TGI & & & & 1.1404 \\
\hline (std. err) & & & & $(0.07)$ \\
\hline Age $>55 \times$ TGI & & & & 1.1307 \\
\hline (std. err) & & & & $(0.07)$ \\
\hline \multicolumn{5}{|l|}{ Control Variables } \\
\hline Number of Trading Rights & 1.0624 & & & 1.0673 \\
\hline (Z-stat) & (6.9) & & & (7.4) \\
\hline Diversification Dummy & & 1.3934 & & 1.4126 \\
\hline (Z-stat) & & (12.2) & & (12.7) \\
\hline Gender $(0=\mathrm{F}, 1=\mathrm{M})$ & & & 1.4259 & 1.4240 \\
\hline (Z-stat) & & & $(15.4)$ & $(15.2)$ \\
\hline Age $\in(25,35]$ & & & & 1.1434 \\
\hline (std. err) & & & & $(0.04)$ \\
\hline Age $\in(35,45]$ & & & & 0.9800 \\
\hline (std. err) & & & & $(0.04)$ \\
\hline Age $\in(45,55]$ & & & & 1.0405 \\
\hline (std. err) & & & & $(0.05)$ \\
\hline Age $>55$ & & & & 0.8889 \\
\hline (std. err) & & & & $(0.04)$ \\
\hline \multicolumn{5}{|l|}{ Parameters } \\
\hline$p$-parameter & 0.7290 & 0.7313 & 0.7309 & 0.7366 \\
\hline (std. err) & $(0.0035)$ & $(0.0035)$ & $(0.0035)$ & $(0.0036)$ \\
\hline
\end{tabular}


old investors to have a relative age hazard ratio of 1.0000 . The $(25,35]$ bracket is therefore 1.0821 times more likely to sell a stock at a loss than the youngest investors. By comparison, the $>55$ bracket avoids losses as can be seen from the 0.8653 hazard ratio. The relative difference between the $(25,35]$ bracket and the $>55$ bracket is statistically significant as can be seen from the standard errors (the difference in hazard ratios is 1.0821 vs. 0.8653 ).

\subsubsection{Investor Sophistication and Gains}

Table IVb examines the propensity of investors to sell (or hold) winners. The hazard ratios give the same qualitative picture as those in Table IVa. For example, in Table IVb Regression 4, we see that the diversification indicator is correlated with decreased propensity to sell winners ( 0.8432 hazard ratio with a $-4.6 Z$-stat). A decrease in the propensity to sell winners in this case indicates the disposition effect is attenuated for more sophisticated investors.

\subsection{DOES SOPHISTICATION ELIMINATE THE DISPOSITION EFFECT?}

To understand the relationship between investor sophistication and the disposition effect, we calculate the total hazard ratio of selling a stock for a loss. A thirtyyear old male investor with five trading rights and two or more stocks in his initial portfolio is marginally prone to the disposition effect $\left(0.3638 \times 1.0651^{5} \times 1.1942\right.$ $\times 1.3652 \times 1.0821=0.8797)$. Notice that the total hazard ratio lies between the sample average from Table III and the value (1.0000) which indicates no sensitivity to losses: $0.6321<0.8797<1.0000$.

This result is striking. Investors who we hypothesize are the most sophisticated suffer much less from the disposition effect with respect to losses than the average investor in our sample does. We can calculate that sophisticated investors have a reduced sensitivity to losses of at least $67 \%$. This result is different from existing published work that shows the disposition effect is prevalent and strong in professional CBOT traders and other investors who are generally thought of as sophisticated. ${ }^{16}$

\subsubsection{An Asymmetric Relationship}

Our results highlight an asymmetric relationship between sophistication and the disposition effect. The same thirty-year old male investor with five trading rights and two or more stocks in his initial portfolio continues to be sensitive to gains $\left(7.0095 \times 0.9506^{5} \times 0.8432 \times 0.7418 \times 0.9287=3.1606 \gg 1.0000\right)$. Notice the total hazard ratio again lies between the sample average from Table III and the

\footnotetext{
$1667 \%$ is the percent difference from the sample average. In other words, the percent difference between $(0.6321-1.0000)$ and $(0.8797-1.0000)$. This value is conservative since measuring the percent difference between an unsophisticated investor and a sophisticated investor would give a larger value.
} 
value (1.0000) which indicates no sensitivity to gains: $4.3842>3.1606>1.0000$. We can calculate that sophisticated investors have reduced sensitivity to gains of at least $36 \%$. Sophistication does not eliminate the disposition effect with respect to gains, but the behavior is significantly dampened. ${ }^{17,18}$

The asymmetric relationship also applies to the hazard ratios associated with all individual covariates. If we look at trading rights, we see that each trading right increases an investors' propensity to sell for a loss by $6.51 \%$ (see the hazard ratio of 1.0651 in Table IVa, Regression 4.) while each trading right decreases an investor's propensity to sell at a gain by $4.94 \%$ (see the hazard ratio of 0.9506 in Table IVb, Regression 4.) The diversification indicator has a $+19.42 \%$ effect for losses and $-15.68 \%$ effect for gains. The gender dummy has $+36.52 \%$ effect for losses and $-25.82 \%$ effect for gains. The $(25,35]$ year old indicator has a $+8.21 \%$ for losses and $\mathrm{a}-7.13 \%$ effect for gains. In each case, the partial effect with regards to gains and losses is close in magnitude and opposite in sign. But, the effect with regards to losses is always stronger.

Why do we see this asymmetric relationship? One explanation may be the way investors form mental accounts. ${ }^{19}$ Mental accounting and prospect theory suggest that losses should be combined whereas gains should be divided. Rather than focusing on whether or not to realize a loss for an individual stock, investors might be focusing on the bigger question of whether to realize a loss at all. As an investor becomes more sophisticated, he may focus on the big issue of losses which could lead to the attenuation of loss aversion that we measure.

Lim (2004) provides evidence that US individual investors are more likely to bundle sales of losers than they are to bundle sales of winners. We test this directly with our data. The distribution of loss bundles is almost identical to the distribution of gain bundles in our data. ${ }^{20}$ This indicates that our investors are not combining their losses more than gains. It is possible that mental accounts come into play only when an investor holds relatively more stocks. We re-check our data and only consider accounts-holdings of seven or more stocks. Again, the distribution of combining losses is almost identical to the distribution of combining gains. It is possible that observable actions (sales) are not a good proxy for unobservable mental accounts. At this point, mental accounts are unable to explain the link between investor sophistication, selling for a loss, and selling for a gain.

$1736 \%$ is the percent difference from the sample average. In other words, the percent difference between (4.3842-1.0000) and (3.1606-1.0000). Again, this value is conservative since measuring the percent difference between an unsophisticated investor and a sophisticated investor would give a larger value.

18 O'Connell and Teo (2003) highlight asymmetric risk-taking behavior with respect to past gains and losses.

19 We thank the referee for suggesting this explanation.

20 To measure the distribution of loss bundles, we count the fraction of sales-dates with one stock sold, two stocks sold, three stocks sold, etc. We do the same for gain bundles. The loss and gain distributions are very similar, especially when considering bundles of multiple stocks. 


\section{Investor Experience and Changes in Behavior Over Time}

We investigate changes in behavior over time. Unlike the fixed demographic covariates used in the last section, we specifically construct a right-hand side variable that changes over time (such a variable is called a "time-varying covariate".) We focus on identifying a time-varying covariate that actually measures changing experience and not other factors such as luck. ${ }^{21}$ Therefore, we define experience to be:

Experience $_{i, t}=$ Number of positions taken by investor $i$ up until date $t$.

In other words, every day, for every stock position, we measure experience by the number of positions an investor has taken. We use this time-varying covariate as a control variable. More importantly, we focus on the interaction of the time-varying covariate and the Trading Gain or Loss Indicator. We do not require experience estimates to follow a parametric specification. Instead, we group an investor's trading life into the first five trades which are labeled [1st, 5th], the next five trades [6th, 10 th], and so on until we end with the $\geq 41$ st trade. ${ }^{22}$

Table I gives some overview statistics about our experience measure. For a given investor, the maximum experience number equals the number of positions taken during our sample period. We see the average investor takes 14.32 positions over our sample period. By construction, our experience measure is zero for each investor at the start of his or her trading life/career. Since this paper examines accounts opened on or after January 1, 1999, the average experience measure across all investors in our sample is zero at the start of our sample period. ${ }^{23}$

In Table Va, Regression 1 we see a hazard ratio of 0.4843 for the interaction term when the investor has one to five trades-worth of experience. The hazard ratio associated with selling stock for a loss increases as an investor gains experience. By the time the investor places his 16th to 20th trade, the hazard ratio is up to 0.6194 with a 0.034 standard error. We can say that sensitivity to losses has decreased by $26 \%$ at the time of the 16 th trade. By the time an investor places his 41 st trade there is a $72 \%$ reduction in sensitivity. ${ }^{24}$

\footnotetext{
21 Consider two investors who open accounts on the same day and are equally prone to the disposition effect. One year after opening their accounts, one investor has been lucky (her portfolio has gone up by $50 \%$ ) and one has been unlucky (his portfolio has fallen by $50 \%$ ). If we use a time-varying measure of portfolio value as a measure of experience, we would rank one investor as three times more experienced than the other even though both have only been investing for one year.

22 List (2003) reports results for linear and quadratic specifications. The author notes higher order terms are tested as well.

23 For readers who are interested, we can calculate an average experience measure across all investors for any date $t$. This average is influenced by investors who are actually holding stocks on date $t$, new investors entering the market, and experienced investors exiting. This said, the average measure in our sample grows to about fifteen where it remains approximately constant.

$2472 \%$ is the percent change in sensitivity from $(0.4843-1.0000)$ to $(0.8556-1.0000)$. Also, please note that Table Va, Regression 2 controls for recent returns, but we discuss these results in the Section 5.1. For the time being, it suffices to say that results related to experience do not change qualitatively.
} 
Table Va. Trading losses and experience

This table presents hazard ratios associated with an individual's decision to sell/hold stocks. The left-hand side variable takes a value of zero every day the individual holds a stock, and one every day s/he sells a stock. Right-hand side variables vary over time and across individuals. The Trading Loss Indicator (TLI) takes a value of one every day a stock is trading below its purchase price, and zero otherwise. "Experience" measures cumulative number of positions an individual has taken at each point in time. We interact "Experience" with the TLI in order to measure changes in an individual's propensity to hold losers. Other variables include each stock's past returns (in Regressions 2 \& 3) and demographic variables (in Regression 3 only). The demographic variables are described in the text. We use a Weibull distribution to parameterize the hazard function. Data are from January 1999 to December 2000. The table reports robust standard errors that allow for clustering by position (a single position is taken by a single investor in a particular stock-please see text for further details.) The standard errors are shown in parenthesis to the right of the hazard ratios.

\begin{tabular}{|c|c|c|c|c|c|c|}
\hline & \multicolumn{2}{|c|}{ Reg 1} & \multicolumn{2}{|c|}{$\operatorname{Reg} 2$} & \multicolumn{2}{|c|}{ Reg 3} \\
\hline & Ratio & Std. err & Ratio & Std. err & Ratio & Std. err \\
\hline \multicolumn{7}{|l|}{ Disposition Effect Variables } \\
\hline Experience $\in[1 \mathrm{st}, 5 \mathrm{th}] \times \mathrm{TLI}$ & 0.4843 & $(0.015)$ & 0.5969 & $(0.019)$ & 0.4433 & $(0.036)$ \\
\hline Experience $\in[6 \mathrm{th}, 10 \mathrm{th}] \times \mathrm{TLI}$ & 0.5393 & $(0.021)$ & 0.6586 & $(0.026)$ & 0.4751 & $(0.042)$ \\
\hline Experience $\in[11 \mathrm{th}, 15 \mathrm{th}] \times \mathrm{TLI}$ & 0.5788 & $(0.026)$ & 0.7158 & $(0.033)$ & 0.5235 & $(0.048)$ \\
\hline Experience $\in[16$ th, 20 th $] \times$ TLI & 0.6194 & $(0.034)$ & 0.7737 & $(0.044)$ & 0.5513 & $(0.055)$ \\
\hline Experience $\in[21 \mathrm{st}, 25 \mathrm{th}] \times \mathrm{TLI}$ & 0.6147 & $(0.039)$ & 0.7617 & $(0.050)$ & 0.5541 & $(0.058)$ \\
\hline Experience $\in[26$ th, 30 th $] \times$ TLI & 0.7173 & $(0.054)$ & 0.9058 & $(0.072)$ & 0.6589 & $(0.074)$ \\
\hline Experience $\in[31 \mathrm{st}, 35 \mathrm{th}] \times \mathrm{TLI}$ & 0.7056 & $(0.055)$ & 0.8879 & $(0.070)$ & 0.6529 & $(0.074)$ \\
\hline Experience $\in[36$ th, 40 th $] \times$ TLI & 0.7309 & $(0.067)$ & 0.9372 & $(0.091)$ & 0.6702 & $(0.083)$ \\
\hline Experience $\in 41$ st $\times$ TLI & 0.8556 & $(0.032)$ & 1.0610 & $(0.041)$ & 0.7455 & $(0.069)$ \\
\hline Number of Trading Rights $\times$ TLI & & & & & 1.0362 & $(0.013)$ \\
\hline Diversification Dummy × TLI & & & & & 1.1473 & $(0.044)$ \\
\hline Gender $(0=F, 1=M) \times$ TLI & & & & & 1.2997 & $(0.043)$ \\
\hline Age $\in(25,35] \times$ TLI & & & & & 1.0495 & $(0.050)$ \\
\hline Age $\in(35,45] \times$ TLI & & & & & 0.7860 & $(0.044)$ \\
\hline Age $\in(45,55] \times$ TLI & & & & & 0.8274 & $(0.053)$ \\
\hline Age $>55 \times$ TLI & & & & & 0.8380 & $(0.058)$ \\
\hline \multicolumn{7}{|l|}{ Control variables } \\
\hline Experience $\in[1 \mathrm{st}, 5 \mathrm{th}]$ & 1.1912 & $(0.031)$ & 1.1874 & $(0.031)$ & 1.1877 & $(0.031)$ \\
\hline Experience $\in[6 \mathrm{th}, 10 \mathrm{th}]$ & 1.2185 & $(0.036)$ & 1.2152 & $(0.036)$ & 1.2103 & $(0.036)$ \\
\hline Experience $\in[11$ th, 15 th $]$ & 1.3411 & $(0.045)$ & 1.3252 & $(0.049)$ & 1.3198 & $(0.045)$ \\
\hline Experience $\in$ [16th, 20th $]$ & 1.5069 & $(0.058)$ & 1.4983 & $(0.059)$ & 1.4919 & $(0.060)$ \\
\hline Experience $\in[21 \mathrm{st}, 25 \mathrm{th}]$ & 1.5660 & $(0.070)$ & 1.5253 & $(0.071)$ & 1.5209 & $(0.071)$ \\
\hline Experience $\in$ [26th, 30th] & 1.6393 & $(0.087)$ & 1.6197 & $(0.088)$ & 1.6122 & $(0.087)$ \\
\hline Experience $\in[31 \mathrm{st}, 35 \mathrm{th}]$ & 1.7670 & $(0.087)$ & 1.7093 & $(0.086)$ & 1.7018 & $(0.086)$ \\
\hline Experience $\in[36 \mathrm{th}, 40 \mathrm{th}]$ & 2.4738 & $(0.067)$ & 2.4149 & $(0.067)$ & 2.3647 & $(0.068)$ \\
\hline Return $[\mathrm{t}-1, \mathrm{t}-5]$ & & & 32.9230 & $(2.472)$ & 32.3091 & $(2.415)$ \\
\hline Return [t-6, t-10] & & & 3.9168 & $(0.327)$ & 3.8962 & $(0.322)$ \\
\hline Return $[\mathrm{t}-11, \mathrm{t}-15]$ & & & 2.3748 & $(0.207)$ & 2.3987 & $(0.205)$ \\
\hline Return $[\mathrm{t}-16, \mathrm{t}-20]$ & & & 1.0967 & $(0.020)$ & 1.0977 & $(0.021)$ \\
\hline + Demographic Controls & & & & & Yes & \\
\hline \multicolumn{7}{|l|}{ Parameters } \\
\hline$p$-parameter & 0.8138 & $(0.004)$ & 0.8508 & $(0.004)$ & 0.8559 & $(0.004)$ \\
\hline
\end{tabular}


Table $V b$. Trading gains and experience

This table presents hazard ratios associated with an individual's decision to sell/hold stocks. The left-hand side variable takes a value of zero every day the individual holds a stock, and one every day s/he sells a stock. Right-hand side variables vary over time and across individuals. The Trading Gain Indicator (TGI) takes a value of one every day a stock is trading above its purchase price, and zero otherwise. "Experience" measures cumulative number of positions an individual has taken at each point in time. We interact "Experience" with the TGI in order to measure changes in an individual's propensities to sell winners. Other variables include each stock's past returns (in Regressions 2 \& 3) and demographic variables (in Regression 3 only). The demographic variables are described in the text. We use a Weibull distribution to parameterize the hazard function. Data are from January 1999 to December 2000. The table reports robust standard errors that allow for clustering by position (a single position is taken by a single investor in a particular stock-please see text for further details.) The standard errors are shown in parenthesis to the right of the hazard ratios.

\begin{tabular}{|c|c|c|c|c|c|c|}
\hline & \multicolumn{2}{|c|}{ Reg 1} & \multicolumn{2}{|c|}{$\operatorname{Reg} 2$} & \multicolumn{2}{|c|}{$\operatorname{Reg} 3$} \\
\hline & Ratio & Std. err & Ratio & Std. err & Ratio & Std. err \\
\hline \multicolumn{7}{|l|}{ Disposition Effect Variables } \\
\hline Experience $\in[1 \mathrm{st}, 5$ th $] \times$ TGI & 4.8943 & $(0.148)$ & 4.4564 & $(0.137)$ & 6.1856 & $(0.485)$ \\
\hline Experience $\in[6$ th, 10 th $] \times$ TGI & 4.7985 & $(0.184)$ & 4.3897 & $(0.171)$ & 6.0471 & $(0.527)$ \\
\hline Experience $\in[11$ th, 15 th $] \times$ TGI & 4.6456 & $(0.205)$ & 4.1800 & $(0.186)$ & 5.8997 & $(0.518)$ \\
\hline Experience $\in[16 \mathrm{th}, 20 \mathrm{th}] \times$ TGI & 4.7308 & $(0.254)$ & 4.2653 & $(0.232)$ & 6.1314 & $(0.580)$ \\
\hline Experience $\in[21 \mathrm{st}, 25 \mathrm{th}] \times$ TGI & 4.7925 & $(0.303)$ & 4.3387 & $(0.280)$ & 6.1403 & $(0.621)$ \\
\hline Experience $\in[26$ th, 30 th $] \times$ TGI & 4.2301 & $(0.289)$ & 3.7883 & $(0.267)$ & 5.3882 & $(0.532)$ \\
\hline Experience $\in[31 \mathrm{st}, 35 \mathrm{th}] \times$ TGI & 4.2873 & $(0.344)$ & 3.8757 & $(0.312)$ & 5.4482 & $(0.613)$ \\
\hline Experience $\in[36 \mathrm{th}, 40 \mathrm{th}] \times$ TGI & 4.1817 & (0.358) & 3.7414 & $(0.327)$ & 5.3955 & $(0.620)$ \\
\hline Experience $\in 41$ st $\times$ TGI & 3.6953 & $(0.126)$ & 3.3438 & $(0.118)$ & 4.9473 & $(0.434)$ \\
\hline Number of Trading Rights $\times$ TGI & & & & & 0.9651 & $(0.011)$ \\
\hline Diversification Dummy $\times$ TGI & & & & & 0.8474 & $(0.031)$ \\
\hline Gender $(0=\mathrm{F}, 1=\mathrm{M}) \times$ TGI & & & & & 0.7620 & $(0.024)$ \\
\hline Age $\in(25,35] \times$ TGI & & & & & 0.9430 & (0.044) \\
\hline Age $\in(35,45] \times$ TGI & & & & & 1.1744 & $(0.064)$ \\
\hline Age $\in(45,55] \times$ TGI & & & & & 1.2012 & $(0.076)$ \\
\hline Age $>55 \times$ TGI & & & & & 1.1525 & $(0.076)$ \\
\hline \multicolumn{7}{|l|}{ Control variables } \\
\hline Experience $\in[1 \mathrm{st}, 5 \mathrm{th}]$ & 1.2978 & $(2.046)$ & 1.2855 & $(0.047)$ & 1.2559 & $(0.046)$ \\
\hline Experience $\in[6$ th, 10 th $]$ & 1.4181 & $(0.056)$ & 1.4232 & $(0.056)$ & 1.3976 & $(0.056)$ \\
\hline Experience $\in[11$ th, $15 \mathrm{th}]$ & 1.5881 & $(0.072)$ & 1.5878 & $(0.072)$ & 1.5303 & $(0.071)$ \\
\hline Experience $\in[16 \mathrm{th}, 20 \mathrm{th}]$ & 1.8012 & $(0.096)$ & 1.7967 & $(0.097)$ & 1.7583 & $(0.096)$ \\
\hline Experience $\in[21 \mathrm{st}, 25 \mathrm{th}]$ & 2.1226 & $(0.127)$ & 2.1183 & $(0.130)$ & 2.0683 & $(0.126)$ \\
\hline Experience $\in$ [26th, 30th] & 2.1925 & $(0.131)$ & 2.1895 & $(0.133)$ & 2.1574 & $(0.130)$ \\
\hline Experience $\in[31 \mathrm{st}, 35 \mathrm{th}]$ & 2.4098 & $(0.171)$ & 2.3989 & $(0.172)$ & 2.3083 & $(0.163)$ \\
\hline Experience $\in$ [36th, 40th] & 3.7677 & $(0.134)$ & 3.7351 & $(0.134)$ & 3.4650 & $(0.126)$ \\
\hline Return $[\mathrm{t}-1, \mathrm{t}-5]$ & & & 4.5242 & $(0.357)$ & 4.4888 & $(0.355)$ \\
\hline Return $[\mathrm{t}-6, \mathrm{t}-10]$ & & & 1.7410 & $(0.147)$ & 1.7365 & $(0.147)$ \\
\hline Return $[\mathrm{t}-11, \mathrm{t}-15]$ & & & 1.4289 & $(0.122)$ & 1.4337 & $(0.122)$ \\
\hline Return $[\mathrm{t}-16, \mathrm{t}-20]$ & & & 1.0435 & $(0.024)$ & 1.0434 & $(0.024)$ \\
\hline + Demographic Controls & & & & & Yes & \\
\hline \multicolumn{7}{|l|}{ Parameters } \\
\hline$p$-parameter & 0.7852 & $(0.004)$ & 0.8040 & $(0.004)$ & 0.8083 & $(0.004)$ \\
\hline
\end{tabular}


In Table $\mathrm{Vb}$, Regression 1 we see a hazard ratio of 4.8943 for the interaction term when the investor has one to five trades-worth of experience. The hazard ratio associated with selling a stock for a gain decreases as an investor gains experience. By the time the investor places his 16th to 20th trade, the hazard ratio is down to 4.7308 with a 0.254 standard error. We can say that sensitivity to losses has decreased by only $4.2 \%$ at the time of the 16th trade. But, by the time an investor places his 41 st trade there is a $31 \%$ reduction in sensitivity to gains. ${ }^{25}$ The same asymmetry found in the sophistication results is clearly present in the time series results.

\subsection{EXPERIENCE CURVES}

The hazard ratios associated with trading experience allow us to draw out "experience curves." Figure 2, Panel A shows the experience curve based on the hazard ratios from Table Va, Regression 1 (along with associated fitted 95\% confidence intervals.) While experience alone does not totally eliminate the disposition effect, the hazard ratio approaches 1.0000 (the value indicating no sensitivity to losses.) In an investor's first twenty trades, the hazard ratio associate with selling for a loss goes from 0.4843 to 0.6194 which is the $26 \%$ reduction in sensitivity mentioned earlier. When looking at the fitted line, the changes goes from 0.50 to over 0.60 , which represents a $20 \%$ change in the sensitivity to losses.

Figure 2, Panel B again highlights the asymmetric behavior. Experience does attenuate an investor's propensity to sell for a gain. However, even after an investor's 40th trade the hazard ratio of selling for a gain is still over 3.50 (more than $2.5 \mathrm{x}$ the baseline hazard rate.) Our experience curves allow for comparisons and contrasts with results in List (2003). Both papers show the effect of experience on individual behavior. Figure 1 in List's paper shows that dealers who make eleven or more trades in a typical month are no longer subject to the endowment effect. In other words, trading experience appears to completely eliminate the endowment effect. In our study, trading experience alone attenuates the disposition effect but does not fully eliminate it. The difference in the two studies may stem from memorabilia dealers in List's sample having more experience than stock market investors in our sample. The difference may also stem from the need for specific skills when operating in the sports memorabilia market. As discussed in the Introduction, dealers may have to discern quality differences between otherwise similar goods (i.e., two tickets from the same event which differ in quality - one has a crease or blemish.)

A second point of contrast can be seen in Figure 2 of our paper which shows that experience attenuates behavior in an asymmetric fashion. Experience dampens $72 \%$ of an individual's reluctance to sell at a loss, but only dampens $31 \%$ of his propensity to sell at a gain. Since experience has varied effects on stock investor behavior, finding differences between experience, the endowment effect, and the disposition effect is not necessarily surprising.

\footnotetext{
$2531 \%$ is the percent change in sensitivity from (4.8943-1.0000) to (3.6953-1.0000).
} 
Panel A: Losses

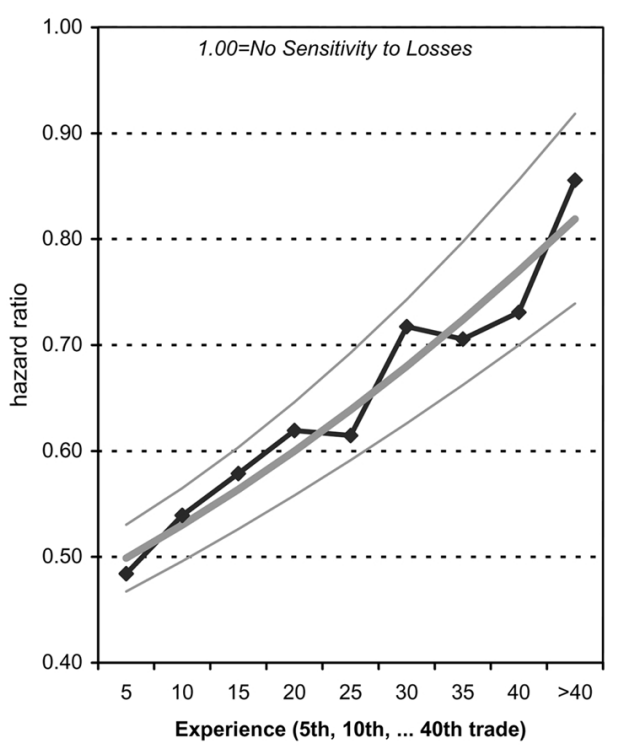

Panel B: Gains

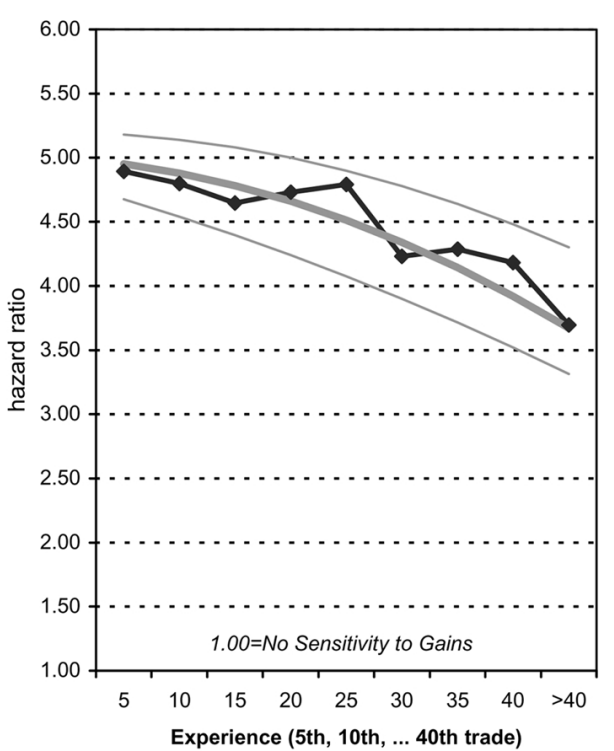

Figure 2. Experience curves. These figures show the relationship between the disposition effect and trading experience. Trading experience is quantified by classifying an investors' 1 st-5th trades; 6th-10th trades, ..., 35th-40th trades. Panel A considers hazard ratios associated with selling a stock for a loss. A hazard ratio of zero indicates investors are unwilling to ever sell a stock at a loss. A hazard ratio of one indicates investors sell stocks that are at a loss at the same rate as the baseline hazard function. Panel B considers hazard ratios associated with selling a stock for a gain. A ratio greater than one indicates investors are eager to sell at a gain. The noisy lines show the nine coefficient estimates. A fitted quadratic curve is shown along with fitted $95 \%$ confidence intervals. Data are from January 1999 to December 2000 and are provided by a large brokerage house in the People's Republic of China.

\subsection{DOES TRADING EXPERIENCE ALONE ELIMINATE THE DISPOSITION EFFECT?}

As can be seen directly from Figure 2, trading experience attenuates, but does not fully eliminate, the disposition effect. The hazard ratios associated with losses make interpretation particularly simple. Hazard ratios start around 0.50 and reach values over 0.80 by the 40 th trade. Because the hazard ratios do not reach a value of 1.00 in Panel A we conclude the reluctance to realize losses is not fully eliminated. On the gain side, hazard ratios fall from 5.00 to near 3.50 by the 40th trade. Because hazard ratios do not reach a value of 1.00 in Panel B we conclude that the propensity to sell for gains is not eliminated. 


\subsection{DO SOPHISTICATION and EXPERIENCE ELIMINATE THE DISPOSITION EFFECT?}

We now ask whether a combination of investor sophistication and trading experience can reasonably eliminate the disposition effect. Table Va, Regression 3 presents hazard ratios from a regression that includes both fixed demographic variables and time-series variables. We see that a thirty year old male, with five trading rights and more than two stocks in his initial portfolio is no longer loss averse by the time he places his 16 th trade $\left(0.5513 \times 1.0362^{5} \times 1.1473 \times 1.2997\right.$ $\times 1.0495=1.00306 \geq 1.0000)$. In other words, sophistication and experiences totally eliminate the reluctance to sell at a loss.

Again, the asymmetric relationship becomes apparent. The same thirty year old male, with five trading rights, more than two stocks in his initial portfolio, and 16 trades worth of experience continues to exhibit a high propensity to realize gains $\left(6.1314 \times 0.9651^{5} \times 0.8474 \times 0.7620 \times 0.9430=3.1259 \gg 1.0000\right)$. Notice the total hazard ratio is between the sample average 4.3842 from Table III and the value (1.0000) which indicates no sensitivity to gains. At most, sophistication and experience reduces investors sensitivity to gains by $37 \%$.

Figure 3 shows experience curves for investors in the $(25,35]$ year old age group and investors over 45 year old. ${ }^{26}$ Younger investors start their trading lives/careers less sensitive to losses and their behavior evolves slightly more rapidly.

It is interesting to note that the inclusion of trading experience indicators and past returns in Tables $\mathrm{Va}$ and $\mathrm{Vb}$ does not qualitatively change results based on sophistication (demographic) variables only (i.e., results from Table IVa and IVb.) While such a finding is comforting, Section 5 tests a number of specific alternative hypotheses.

\subsection{COMPARISON WITH PREVIOUS STUDIES}

Table Va, Regression 3 contains both sophistication and experience variables. It also contains a host of control variables (some of which are listed as "Demographic Controls" without the associated hazard ratios to save space.) One of the controls is gender which has a hazard ratio of 1.0249 with a 0.0181 standard error and is thus not significantly different from zero. ${ }^{27}$ This finding matches results in Table I, Panel I of Grinblatt and Keloharju (2001). The authors also find that "gender is unrelated to the propensity to sell" and note this result is "curious in that it tends to contradict the results in [Barber and Odean (2001)], who find that men trade more than women do." As the authors also point out, both our Table Va and their Table I

\footnotetext{
26 We combine the $(45,55]$ and $>55$ groups from earlier regressions. Use of the $>55$ alone gives qualitatively similar, albeit noisier, results due to fewer observations.

27 To be clear, the interaction of gender and the TLI is reported in the table, has a positive hazard ratio of 1.2997 , and is statistically significant at all conventional levels. In this section, we are referring to the hazard ratio of the gender indicator alone (i.e., as a control variable.)
} 


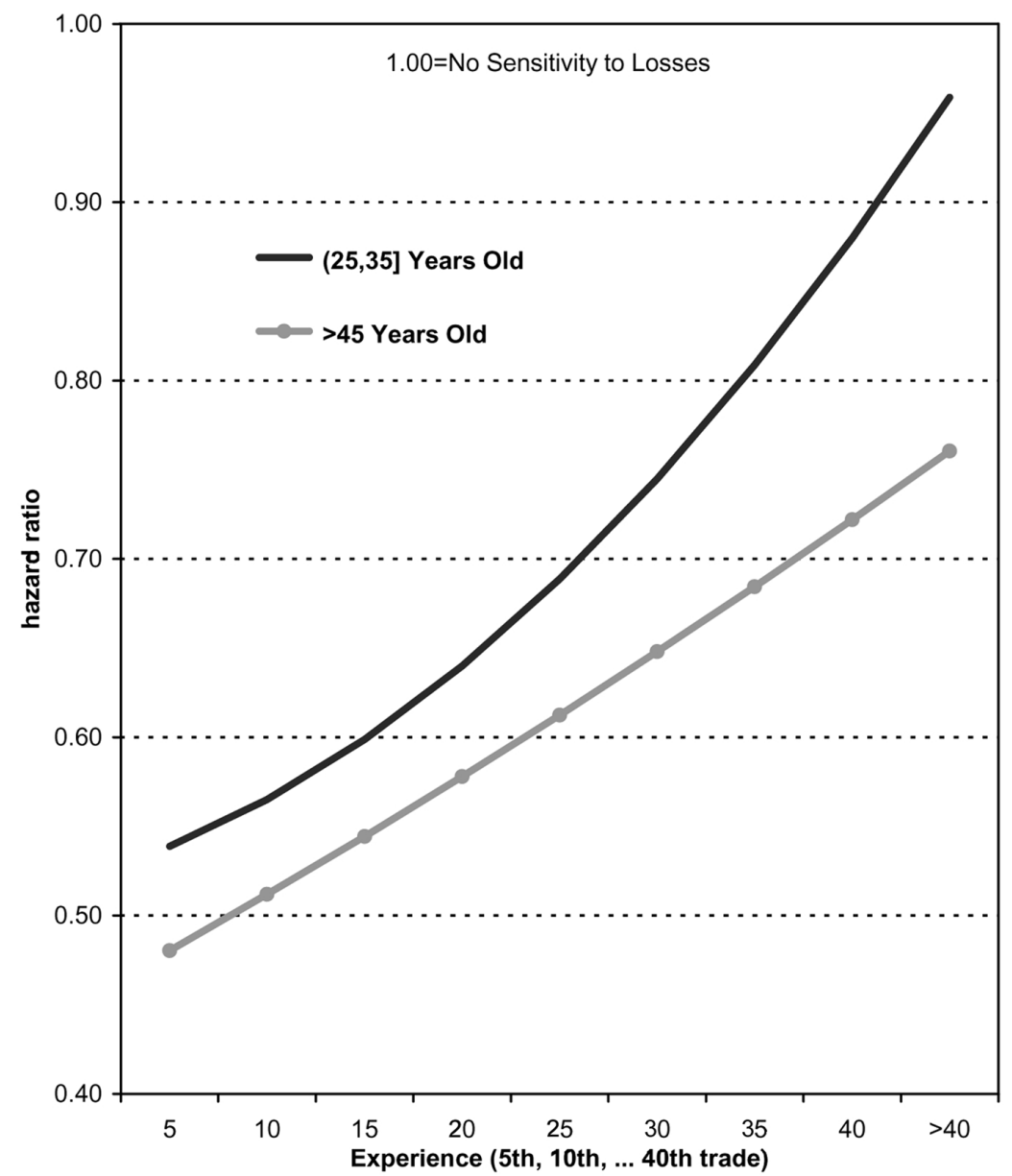

Figure 3. Experience curves for losses by age. This figure shows the relationship between an investor's reluctance to realize losses, trading experience, and age. The 25 to 35 year old experience curve is shown with the top line. The over 45 years old experience curve is shown with the bottom line. Trading experience is quantified by classifying an investors' 1 st-5th trades; 6 th-10th trades, ..., 35 th-40th trades. The figure only considers (fitted) hazard ratios associated with selling a stock for a loss. A hazard ratio of zero indicates investors are unwilling to ever sell a stock at a loss. A hazard ratio of one indicates investors sell stocks that are at a loss at the same rate as the baseline hazard function. Data are from January 1999 to December 2000 and are provided by a large brokerage house in the People's Republic of China.

control for a number of variables that are not considered in the Barber and Odean (2001) study.

We further investigate if gender is related to the propensity to sell. In Table IVa, Regression 4 note that men appear to trade more than women as the hazard ratio on the gender control variable is 1.0750 with a $4.1 \mathrm{Z}$-stat. We next re-do Table III, Regression 1 but add a gender control variable. In this case the hazard ratio on the 
TLI remains at 0.63 but the hazard ratio on the gender control variable is 1.2052 with an $11.96 \mathrm{Z}$-stat. A pattern is now apparent: the more control variables included in a regression (as in Table $\mathrm{Va}$ ), the less gender becomes an important predictor of the propensity to trade. ${ }^{28}$ The fewer control variables included in a regression (as we find when we add a gender control variable to Table III), the more gender becomes an important predictor of the propensity to trade.

In summary, our results fit well with findings in Grinblatt and Keloharju (2001). Reconciling our results with results in Barber and Odean (2001) is clearly an area for future research. For example, it is possible that men in Finland and the PRC are not more overconfident than women. In addition to our comparisons regarding the role of gender, Section 5.9 compares results regarding the role of portfolio value with results in Grinblatt and Keloharju (2001).

\section{Alternative Explanations}

In this section, we examine alternative explanations of our results (explanations other than the disposition effect.) This section may be particularly helpful for readers who wonder if investors in the PRC are different from investors in the US, Finland, and Israel. This section is also helpful for readers who question if feedback trading (for example) is actually driving our results.

\subsection{FEEDBACK TRADING}

It is possible that investors in the PRC follow a feedback trading strategy that has little to do with the disposition effect. In particular, investors may be contrarians who sell winners and buy (or at least hold) losers. To test for such effects, we create time-varying covariates for use in our survival analysis.

In Table Va, Regression 2 we include each stock's past returns over certain time intervals $[\mathrm{t}-1, \mathrm{t}-5],[\mathrm{t}-6, \mathrm{t}-10],[\mathrm{t}-11, \mathrm{t}-15]$, and $[\mathrm{t}-16, \mathrm{t}-20]$. We see that hazard ratios associated with Experience $\times T L I$ continue to rise with experience. It is also clear that past returns are closely linked to an individual's decision to sell a stock. The hazard ratio on Return [t-1, t-5] is 32.9230 and statistically significant. The sensitivity to past returns falls off over time to the point that the hazard ratio on Return [t-16, t-20] is 1.0967, but still significant. ${ }^{29}$

While investors do sell recent winners quickly, after controlling for such behavior, our results remain qualitatively unchanged. We reach the same conclusions when considering past returns and selling for a gain. In Table $\mathrm{Vb}$, Regression 2 the hazard ratios associated with Experience $\times$ TGI continue to fall even after

\footnotetext{
28 Technically, we measure the propensity to sell, but since $70 \%$ of all transactions involve one buy and one sell, the propensity to sell is highly correlated with the propensity to trade.

29 So as not to censor our sample, we use past returns regardless of how long a position has been held. This is important, otherwise the inclusion of Returns [t-16, t-20] would preclude positions held less than twenty days.
} 
including past returns. We again see that past returns are linked to an increased probability of sale (just as they are in Table Va). Again, the inclusion of past returns does little to change the hazard ratios associated with Experience $\times T G I$. Thus, we conclude that past returns do influence the decision to sell (vs. hold) a stock. A large, recent gain in a stock's price is associated with an increased probability of sale. However, this association is separate from the disposition effect. The reference price continues to play an economically and statistically significant role in an individual's decision to sell (vs. hold) a stock. Grinblatt and Keloharju (2001) find comparable results in Finland. Most importantly, including past returns does not change our results regarding investor experience.

\subsection{PERCENTAGE GAIN OR LOSS}

In Appendix E, Regression E-i we include a measure of each position's percentage gain or loss, as well as the Trading Loss Indicator (TLI) or Trading Gain Indicator (TGI.) We calculate the percentage gain (loss) based on each day's closing price and the reference price. The percentage gain or loss has an effect on an investor's propensity to sell winners and hold losers, but the interaction terms (Experience $\times T L I$ remain qualitatively similar to those reported in Table Va, Regression 3. As mentioned earlier, the tables in this paper use the weighted average purchase price as a reference price. We also confirm (not shown) that using the first purchase price or last purchase price as the reference price gives qualitatively similar results.

\subsection{TRADING COSTS}

Harris (1988) suggests that another reason investors might sell winners and hold losers is that they are sensitive to higher trading costs at lower stock prices. But this argument is also unable to explain the disposition effect in our study. Unlike in the US, transaction costs in the PRC are regulated by the government. Fees and taxes are set at a predetermined rate $(0.40 \%)$ of the transacted amount. The investors in our data pay the same proportion in transaction costs for high-priced stocks as for low-priced stocks. They are unlikely to avoid trades in lower-priced stocks simply because of transaction costs.

\subsection{PARTIAL VS. LIQUIDATING SALES}

Lakonishok and Smidt (1986) propose that investors sell more winners than losers in order to rebalance their portfolios. If this were the case, the investors in our sample would sell partial holdings of a winning stock. Instead, they sell the entire position almost $80 \%$ of the time (this value can be calculated by adding together the percentages in Table II, Column 1). The Lakonishok and Smidt (1986) proposal does not affect the results of our study because we are already estimating the time to first sale. 


\subsection{OBSERVATION FREQUENCY, STATISTICAL SIGNIFICANCE, AND CLUSTERING}

Does survival analysis with daily data cause us to overstate $Z$-statistics? No, all reported regressions in this paper allow for clustering by individual stock positions. To show this point, we re-estimate Table Va, Regression 3 using weekly data thus cutting our sample size by a factor of almost five. Results using weekly data are reported in Appendix E, Regression E-ii. Both hazard ratios and standard errors are very similar to those using daily data. Conclusion: using weekly data does not change standard errors since we control for clustering by stock position.

\subsection{TIME TREND}

Does our experience measure contains an inherent time trend? Our measure starts at zero on January 1, 1999 by construction. The measure then grows as investors take positions. We re-estimate Table Va, Regression 3 and add a time trend. As Appendix E, Regression E-iii shows, there is a time trend in terms of selling probability, but this trend does not affect the estimated hazard ratios associated with the disposition effect. We also re-estimate Table Va, Regression 3 using different temporal sub-samples and find no qualitative changes.

\subsection{CALENDAR EFFECTS}

Based on results reported in studies such as Odean (1998), do the hazard ratios associated with experience vary systematically by calendar month? We address this question by creating indicator variables for each of the twelve months. We then interact the monthly indicator variables with the Trading Loss Indicator (TLI) and re-estimate Table Va, Regression 3. The results in Appendix E, Regression E-iv show the linearly increasing experience curve remains (there is a slight upward shift in the experience-related hazard rates compared to the base-case). Note that the hazard ratios associated with the month dummies and the hazard ratios associated with the month dummies $\times T L I$ are suppressed to save space. ${ }^{30}$

\subsection{USING ADDITIONAL ACCOUNTS}

This paper only considers trading data from 1,511 accounts opened on or after January 1,1999 . We do this in order to accurately measure the experience variable defined in Equation (3). We now provide an out-of-sample test of our results by

\footnotetext{
30 A more formal comparison of calendar month results -reported in Odean (1998) -is not possible due differences between survival analysis and his PGR and PLR analysis. Future research is warranted since the PRC is a (capital gains) tax-free environment. Although we do not report results for interaction of the TLI and monthly dummies, there is indication that investors in the PRC are even less likely to see losers in December than in July. We need a longer data sample to test properly and save a full investigation for future work.
} 
asking: what would happen if we consider accounts opened before January 1, 1999 along with the 1,511 accounts opened after January 1, 1999? ${ }^{31}$

For some variables such as gender, an increase in the amount of data gives us increased power in our statistical tests without increasing noise. For other variables, the increase in data creates noisy measures. For example, we cannot know certain facts about accounts opened before January 1, 1999. We cannot know how many stocks were in the portfolio the first day a given investor traded. We cannot know if the first trade we observe is the individual's first trade or her second trade or her twenty-first trade.

As a robustness check of earlier results, we use the full sample but expand the number of right-hand side variables in an effort to accommodate accounts opened before January 1, 1999. Specifically, we include two different sets of hazard ratios for the diversification indicator and the experience variables. One set of hazard ratios applies to the censored accounts and one set applies to 1,511 accounts opened after January 1, 1999..$^{32}$ For all other variables, such as gender, we have estimate a single hazard ratio (pooled across both types of accounts.)

The pooled hazard ratios are comparable to results shown in Table Va. Variables such as the interaction of gender and the TLI remain at 1.30 and, as one might predict, the associated standard error drops (to 0.030 from 0.043 ) due to an increase in data. Hazard ratios from the interaction of age and the TLI also remain similar to those reported in Table Va. Again, standard errors go down due to the increase in data. Finally, the experience-related hazard ratios for the 1,511 accounts opened after January 1, 1999 also remain similar to those reported in Table Va. They start at 0.42 for the first five trades and go up to 0.80 for trades greater than or equal to forty-one.

On the other hand, hazard ratios associated with experience for the accounts opened before January 1, 1991 start at 0.49 for the first five trades and go up to 0.91 for trades greater than or equal to forty-one. Thus the experience curve for the censored accounts is essentially parallel to, but lies above, the experience curve for the 1,511 accounts opened after January 1, 1999. This is exactly what one would expect. The first trade we observe for a censored account is not actually the first trade. Therefore, we expect these accounts to be less sensitive to losses than previous results (shown in Table Va) indicate since they have prior trading experience that we do not observe. Finally, the interaction of our diversification indicator and the TLI is no longer significantly positive for the accounts opened before January 1, 1999. Again, this is exactly what one would expect since we cannot know how many stocks were in the portfolio on the first day the investor

\footnotetext{
31 Section 2.2 mentions that our data are from two brokerage branch offices with over 2,900 active accounts. Of these active accounts, 1,511 were opened on or after January 1, 1999. The remaining 1,400 accounts were opened before January 1, 1999.

32 For the censored accounts, we base variable values on our first observation of trading by a given account (most likely soon after January 1, 1999.) These observations are rough (possibly very rough) proxies for the true values which were only observable (not by us) before January 1, 1999.
} 
traded. Since investors are more likely to diversify over time, our diversification indicator variable (for the censored accounts only) becomes noisy and looses most of its economic meaning.

In summary, using censored accounts complicates the analysis. Hazard ratios associated with gender and age, for which censoring is not a problem, do not change materially and benefit from an increase in sample size. We estimate different hazard ratios for variables and accounts where censoring does matter. Hazard ratios associated with experience behave as expected.

\subsection{TIME VARYING MEASURES OF PORTFOLIO VALUE}

Does wealth measure experience? We repeat Table Va, Regression 3 and include a time varying measure of each investor's stock market wealth (actually the natural $\log$ of his portfolio size measured in RMB.) We also interact this measure with the Trading Loss Indicator (TLI) and report results in Appendix E, Regression E-v. We find investors are more likely to realize losses as their equity wealth rises (see the associated 1.0432 hazard ratio with 0.014 standard error.) The 1.0432 hazard ratio on log portfolio value fits well with conclusions in Vissing-Jorgensen (2003): behavior inconsistent with traditional finance theory tends to diminish as investor wealth increases. The hazard ratios associated with sophistication measures and the TLI remain similar to those previously reported in Table Va. For example, the hazard ratios associated with Experience $\times T L I$ shift downward (relative to Table Va) but retain their upward slope. This downward shift comes from allowing the natural $\log$ of equity wealth to partially act as a time-varying measure of experience (i.e., for a given individual, stock market wealth tends to grow over time.) Since equity wealth has a hazard ratio over one and the experience hazard ratios retain their upward slope, we conclude that experience and wealth are not perfect proxies for one another.

Appendix E, Regression E-v allows us to compare our results to those in Grinblatt and Keloharju (2001). We find the hazard ratio on the natural log of investor $i$ 's portfolio value is 0.9007 with a $-14.03 \mathrm{Z}$-stat when considering the control variable. ${ }^{33}$ Both our paper and Grinblatt and Keloharju (2001) report a reduced propensity to sell as household portfolio size increases. The major difference is that that our $Z$-stat is -14.03 while Grinblatt and Keloharju (2001) report a -0.43 $t$-stat at the bottom of their Table I, Panel I.

The difference may come from the fact that Grinblatt and Keloharju (2001) include a set of dummy variables for the number of stocks currently in an investor's portfolio. We re-run Regression E-v with a set of dummy variables like the one used in Grinblatt and Keloharju (2001) and continue to include our wealth variable. The new dummy variable cannot account for the differences between the two papers

\footnotetext{
33 This value is included under "Demographic Controls" but is not reported in the table to save space. The value is different from the interaction of $\ln$ (Port Value) and the TLI which is reported at the top of the table and has a 1.0432 hazard ratio.
} 
as the hazard ratio on the log portfolio size continues to be significantly less than one in our data. We leave our findings as an open question that may be related to differences between Finnish and Chinese investors.

As a final note, our results can also be compared with a recent working paper by Chen et al. (2004). Like our paper, the authors document that the disposition effect exists (on average) when studying individual investors in the PRC. The authors also document that investors with larger accounts (in RMB) are less prone to the disposition effect. This finding is similar in spirit to the 1.0432 hazard ratio we report at the top of Appendix E, Regression E-v. The finding also highlights the benefits of survival analysis over the PGR and PLR analysis used in Chen et al. (2004). The authors report mixed findings because they are unable to control for wealth (or other factors) while at the same time testing if the factor attenuates the disposition effect. Their mixed results probably come from situations such those highlighted in Appendix D, Example 4 (which shows various PGR and PLR measures can both rise and fall as trading activity increases or portfolio holdings increase.)

\subsection{DO INVESTORS ACTIVELY MONITOR STOCKS THEY HAVE SOLD?}

To test for evidence that investors continue to track stocks after selling, we count the number of different tickers a given investor trades. Does an investors trade many different stocks or revisit the same stock on multiple occasions? We use the twelve investors who take exactly twenty-five positions during our sample period as an example: none of the 12 investors trades 25 different tickers; 2 of the 12 trade 18 different tickers; 1 trades 19 different tickers; 2 trade 20 different tickers, and so on. This pattern of taking repeated positions in the same stock holds if we look at investors with other trading frequencies (i.e., those who take some other number of positions during our sample period.) These results provide indirect evidence that investors actively monitor stocks they have sold.

\subsection{EXPERIENCE CURVES AND TRADER TYPE}

Readers may ask if experience curves - similar to those shown in Figure 2, Panel A and Figure 3 - are upward sloping for different types of traders. As we can see in Figure 3, experience curves for young and older traders are both upward sloping. Similar results are found when looking at experience curves for male and female investors. More importantly, similar upward sloping curves are found for high-frequency and low-frequency traders (although, by definition, curves for lowfrequency traders may only extend out to the 10th or 15th position). A benefit of survival analysis is we can draw separate experience curves (such as those shown in Figure 3) for any well-defined group of investor. 


\subsection{CONDITIONAL PROBABILITY OF A SALE AND UNOBSERVED HETEROGENEITY}

We end by discussing a test of whether the (baseline) conditional probability of a sale changes over time. In other words, we ask if the hazard rate is constant. Such a question has economic importance if one believes that investors in our sample are relatively uninformed compared to other market participants. Market makers care about the conditional probability of receiving an uninformed trade (vs. informed) trade. When modeling the hazard function with a Weibull distribution, such a test is equivalent to asking whether the parameter $p$ is equal to one.

At first glace, values of $p$ reported at the bottom of Table III, IVa, IVb, Va, and $\mathrm{Vb}$, indicate the parameter is significantly less than one. For example, in Table Va, we see values of $0.8138 ; 0.8508$; and 0.8559 at the bottom of the three regressions. Such results initially indicate that investors in our sample are more likely to sell soon after purchasing a stock than they are after holding a stock for a month. Of course, our finding could result from having different types of investors in our sample (day traders, weekly re-balancers, monthly-re-balancers, etc.) In fact, an omitted variable could influence the estimation of the baseline hazard function and our coefficient estimates. Statisticians refer to the possible influence as "unobserved heterogeneity" or "frailty" - see Jenkins (2004).

We repeat Table Va, Regression 3 but allow hazard functions to vary by position. Specifically, $h\left(t, p, X, Z_{t}, \alpha_{i}\right)=\alpha_{i} h\left(t, p, X, Z_{t}\right)$ where $i$ is a stock position; and $\alpha_{i}$ is an unobserved effect associated with position $i$. We parameterize the unobserved heterogeneity $\left(\alpha_{i}\right)$ with an Inverse-Gaussian distribution. Appendix E, Regression E-vi presents our results. The exponentiated coefficients $-\exp (\gamma)$ or hazard ratios - are very similar to those in Table Va, Regression 3. Our experience measures slope upward from 0.4236 to 0.8090 and the sophistications measures increase slightly in absolute terms. For example, the ratio associated with gender is 1.1473 Table Va and is 1.1556 in Regression E-vi.

Interestingly, the value of the $p$-parameter is 1.3084 and significantly different from zero. Allowing positions to have different baseline functions leads to different inference about the conditional probability of a sale over time. Importantly, the estimated coefficients remain stable and do not change our inference. We leave additional inquiry for future study.

\section{Summary and Conclusion}

This paper began by asking if investor sophistication and trading experience attenuate (or even eliminate) behavioral biases in financial markets. We study the well-documented disposition effect in detail and come to a number of conclusions: (i) Neither sophistication nor trading experience alone eliminates biases - in this case, the disposition effect; (ii) Together, sophistication and trading experience eliminate the reluctance of investors to realize losses; (iii) There is an asymmetry with regards to trading behavior. Sophistication and trading experience totally elim- 
inate the reluctance to realize losses. On the other hand, sophistication and trading experience reduce the propensity to realize gains by $37 \%$, but fail to eliminate this part of investor behavior.

The three main conclusions are reached by combining a statistical model of investor trading (survival analysis) with carefully constructed measures of sophistication and trading experience. Survival analysis provides a description of how long investors typically hold a stock position before selling. This paper uses hazard ratios to report changes in the probability of selling for different levels of investor sophistication. Hazard ratios also report changes in the probability of selling as an investor's trading experience changes over time. Our measures of investor sophistication are based on static difference across investors at the start of their investing careers. The measures include: the number of trading rights an individual has, an indicator variable of initial portfolio diversification, gender, and age. Our measure of trading experience is a time-varying count variable that increases each time an investor initiates a new position. So as not to impose a functional form on the measure of trading experience, we group an investor's trading life into the first five trades [1st, 5th], the next five trades [6th, 10th], and so on.

In addition to answering questions about financial markets, our paper documents many findings related to the disposition effect. Investors who diversify their portfolios from the start of their investing careers are $15 \%$ more likely to realize a loss than those who initially buy only one stock (i.e., investors who initially diversify are not as reluctant to realize losses.) Men are 30\% more likely to realize a loss than women are. Investors age $25-35$ in the PRC are $20 \%$ more likely to realize losses than investors over 55 are. Differences in behavior compound one another. For example, a thirty year old male with five trading rights and more than two stocks in his initial portfolio is no longer loss averse by the time he places his 16th trade. On the other hand, a fifty-seven year old female with two trading rights and one stock in her initial portfolio is very reluctant to ever sell a stock at a loss. We estimate the probability of her selling for a loss is $60 \%$ less than a baseline hazard rate suggests. The more equity wealth an individual has, the less loss averse they become. Wealth is partially correlated with experience but does not serve as a perfect proxy. Men and women have the same hazard rate of selling after controlling for a host of other factors such as experience, age, and initial portfolio diversification. Finally, recent returns are a strong predictor of sales. At the same time, recent returns do not diminish the importance of a reference price (the price at which the stock was first bought.)

Our results provide a new and more complete understanding of biases than has previously been possible. The effect of experience is not confined to evaluating and trading physical objects such as art or baseball cards. We show that trading experience in a financial market can reduce the magnitude of the disposition effect. These results are similar to, but different from, the effect of experience on the endowment effect. In particular, experience has an asymmetric effect on investor behavior in the face of losses vs. gains. The asymmetry points to a number of areas 
of future research. For example, investors may be subject to another bias (other than the disposition effect) when stocks are trading for a gain. We find no evidence that mental accounts can explain the asymmetry - investors in our sample do not combine their losses differently than gains when selling. It is possible that our indirect evidence based on observed investor actions (selling) is a poor proxy for the actual mental accounting. Alternatively, it is possible that a stock that has been trading for a loss for a long time is sold on the first day its price goes above the purchase price. Such behavior - known as "get even and get out" - might imply a discontinuity in the level of the Kahneman and Tversky (1979) value function. Thus far, psychologists and economists have focused on the discontinuity in the slope of the value function. Future research regarding reference points is warranted.

Finally, our research design focuses on individual brokerage accounts from the time they are first opened. We are able to draw "experience curves" that track the evolution of an individual's behavior over time. Our research design gives us the ability to: i) Follow an individual's behavior instead of measuring average effects for a group of individuals; ii) Observe individual behavior from the start of an investor's trading life/career; iii) Make observations at a daily frequency; and iv) Record transactions from a large financial market setting. Although we test numerous alternative hypotheses that might also explain our results (such as feedback trading, observation frequency, and calendar effects), the conclusions of this study remain highly robust. 


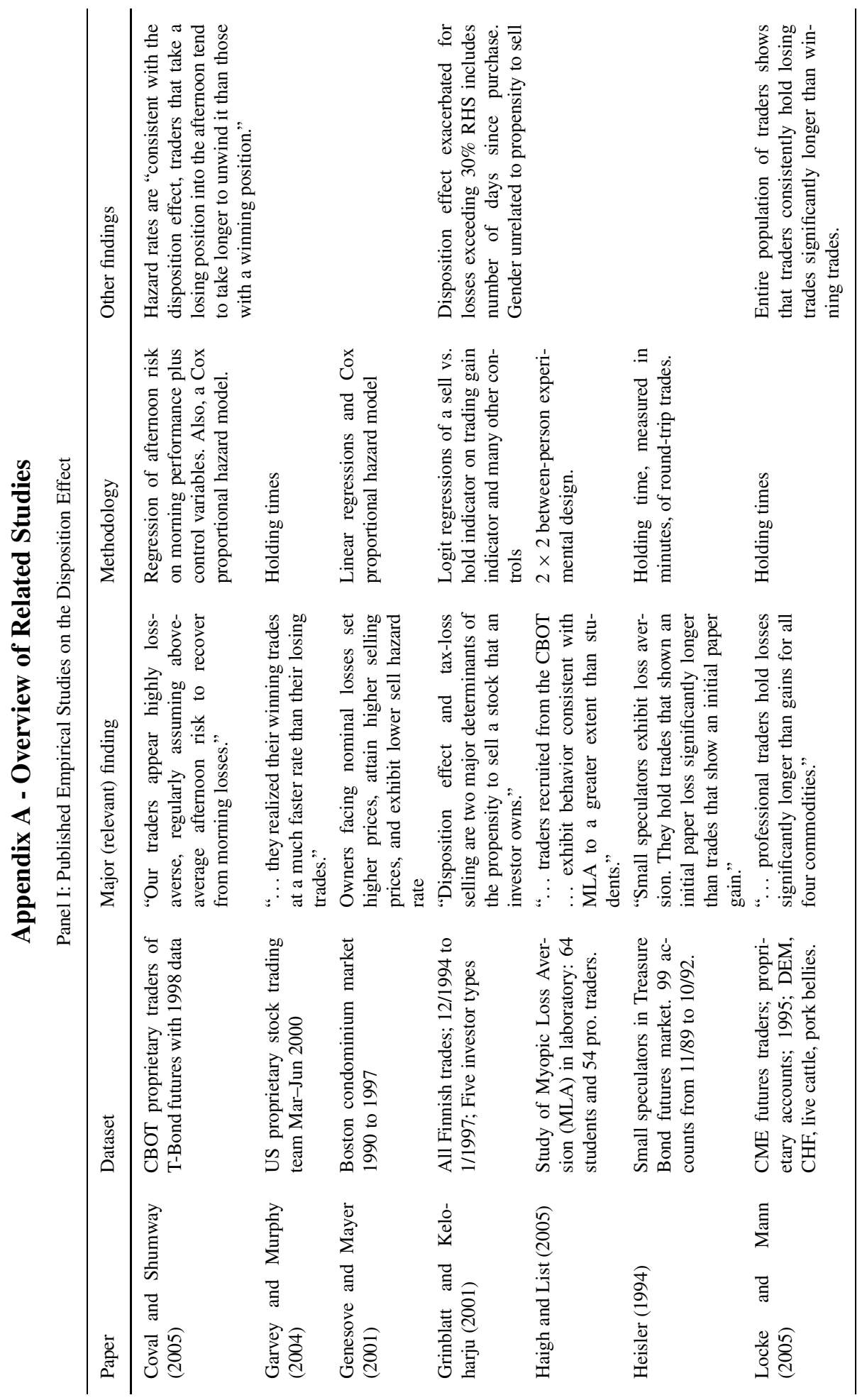




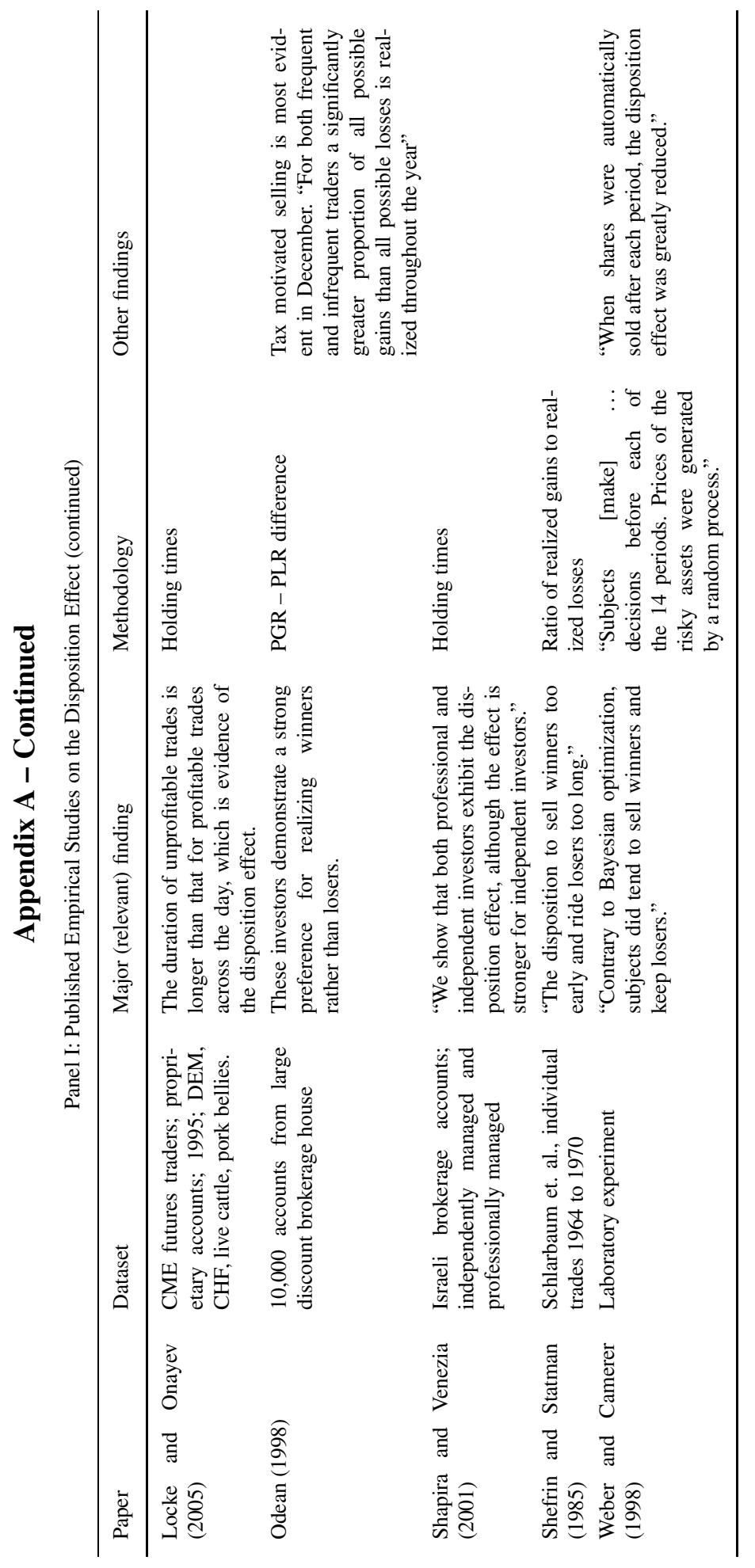


TRADING EXPERIENCE AND BEHAVIORAL BIASES

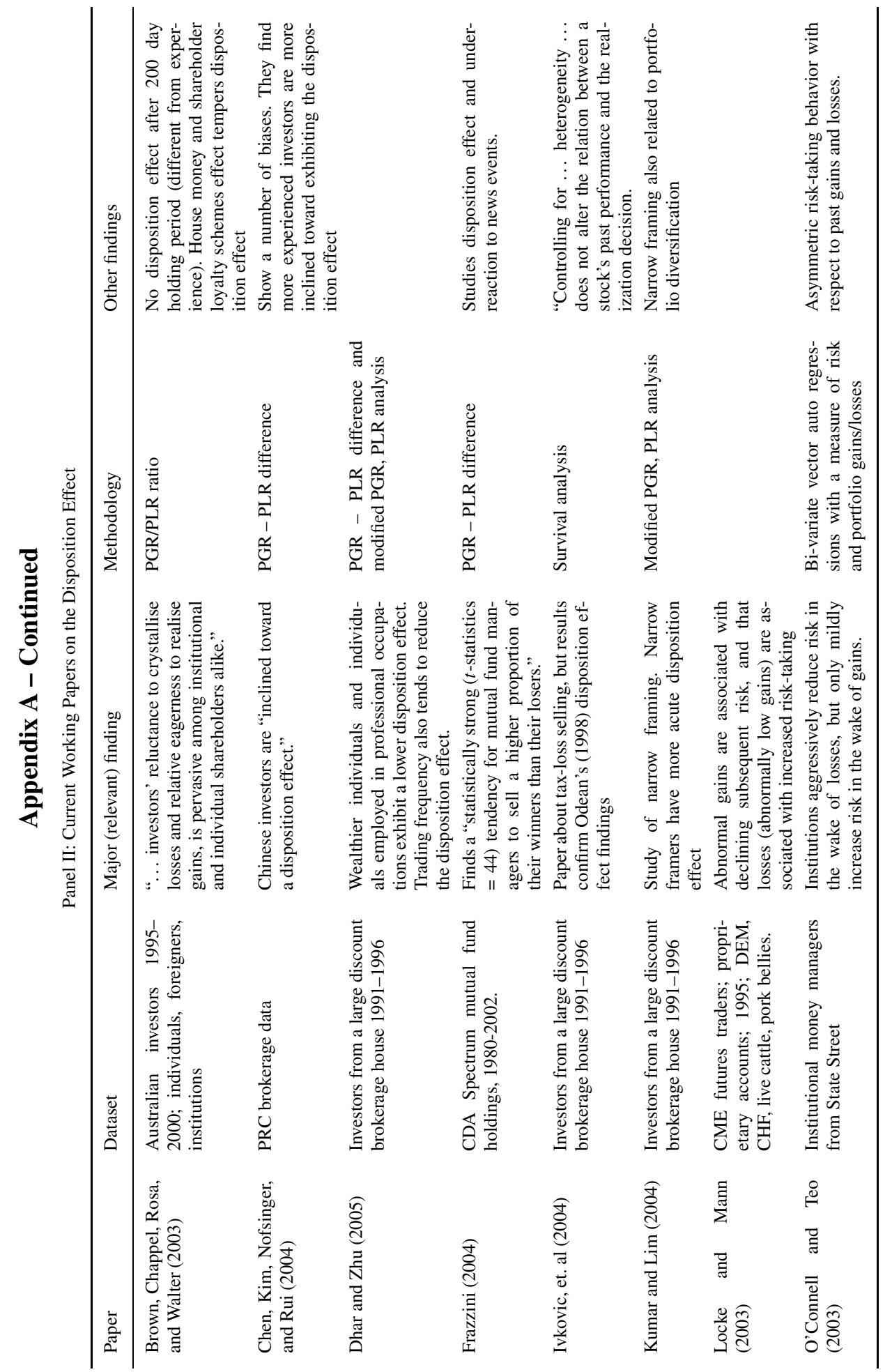




\section{Appendix B. Overview of Survival Analysis}

Consider the random variable $\tilde{T}$ which is the length of time between when a stock is first bought and when it is sold. Assume that $\tilde{T}$ is distributed $f(t)$ so the CDF is:

$$
\begin{gathered}
F(t)=\int_{0}^{t} f(s) d s \\
\operatorname{Prob}(\tilde{T} \leq f)
\end{gathered}
$$

The distribution of survival times is given by:

$$
\begin{array}{r}
S(t)=1-F(t) \\
\operatorname{Prob}(\tilde{T} \geq f)
\end{array}
$$

The hazard rate, $h(t)$, is a measure of conditional probability. Given that the stock has lasted in an investor's portfolio until time $t$, the hazard rate is the probability that the stock will be sold during the next interval of time $(\Delta)$ :

$$
\begin{aligned}
h(t) & =\lim _{\Delta \rightarrow 0} \frac{F(t+\Delta)-F(t)}{\Delta S(t)} \\
& =\frac{f(t)}{S(t)}
\end{aligned}
$$

Weibull hazard functions can be described succinctly with parameter $p$ and constant of integration $\lambda$ :

$$
\begin{aligned}
& f(t)=p \lambda t^{p-1} \exp \left(-\lambda t^{p}\right) \\
& S(t)=\exp \left(-\lambda t^{p}\right) \\
& h(t)=p \lambda t^{p-1}
\end{aligned}
$$

Estimation of an accelerated hazard function that depends on fixed covariates $(X)$ and time varying covariates $\left(Z_{t}\right)$ can be accomplished with maximum likelihood:

$$
h\left(t, p, X, Z_{t}\right)=p \lambda t^{p-1} \exp \left(X \beta+Z_{t} \gamma+\varepsilon_{t}\right)
$$

The hazard ratio of a coefficient measures the change in the hazard rate for a unit change in the associated covariate:

$$
\begin{aligned}
\operatorname{hazard} \operatorname{ratio}(\gamma) & =\frac{h\left(t, p, X, Z_{t}=1\right)}{h\left(t, p, X, Z_{t}=0\right.} \\
& =\exp (\gamma)
\end{aligned}
$$


Estimation of the parameters ( $\beta$ 's and $\gamma$ 's) is done with maximum likelihood. On each day after a stock is bought, the stock is either sold or it survives in the portfolio for another day. The log-likelihood on a given day during our sample period is:

$$
\ln (L)=\sum_{j=1}^{n} d_{j} \ln \left[f_{j}\left(t_{j}\right)\right]+\left(1-d_{j}\right) \ln \left[S_{j}\left(t_{j}\right)\right]-\ln \left[S_{j}\left(t_{0 j}\right)\right]
$$

where $d_{j}$ is an indicator variable that equals one $\left(d_{j}=1\right)$ if stock $j$ is sold on date $t ; f_{j}\left(t_{j}\right)$ is the distribution of selling times; $j=1 \ldots n$ is the observation number; $t_{j}$ is today's date; $S_{j}$ is the survival function; and $t_{0 j}$ is the date the stock entered today's portfolio (when using daily time-varying covariates, all stocks that are in the portfolio today, have effectively been "rolled-over" from yesterday's portfolio.) The log-likelihood function follows from the definition of the hazard function given on the previous page.

We use STATA for estimation and the company provides references in their manual Survival Analysis and Epidemiological Tables. The case of Weibull hazard model is shown in the section "streg" on page 233-234.

\section{Appendix C. Example Using Survival Analysis}

Existing papers typically examine an investor's portfolio on a sales date (only) when testing for the disposition effect. While there is nothing wrong with such methods, we propose there is additional information on the days between a stock's purchase date and sales date. To see the value of this information, we provide a highly stylized example.

Consider four different investors, who buy four different stocks at $\$ 10$ per share. Each investor holds the position for twenty days before selling at $\$ 11$ per share, so each investor realizes a $10 \%$ return before transaction costs. The only difference between the investors is the price path their stocks follow between their purchase on day zero and the sale on day twenty. Figure $\mathrm{C}$ (below) shows the four different hypothetical price paths experienced by the four investors.

We can look at data other than the purchase price and sale price in Figure C. Investor A buys his stock at $\$ 10$ per share, sees it fall to $\$ 9$ per share one day later. The stock stays at $\$ 9$ per share until day twenty, when it jumps up to $\$ 11$. Investor B buys her stock at $\$ 10$, where it remains until day twenty, when it jumps up to $\$ 11$. Investor $\mathrm{C}$ buys his stock at $\$ 10$, and sees it move to $\$ 11$ on day one, where it remains until day twenty. Finally, Investor D buys her stock at $\$ 10$, and sees it jump to $\$ 12$ per share on the first day, where it remains until day twenty. On day twenty, Investor D's stock falls to $\$ 11$ per share.

We now ask, which investor (if any) is most prone to the disposition effect and which is least prone? Inferring which investor may be prone to the disposition effect is difficult. Clearly, all investors realize equal 10\% returns. Odean (1998) includes other stocks in an investor's portfolio at the time of a sale in his tests for 


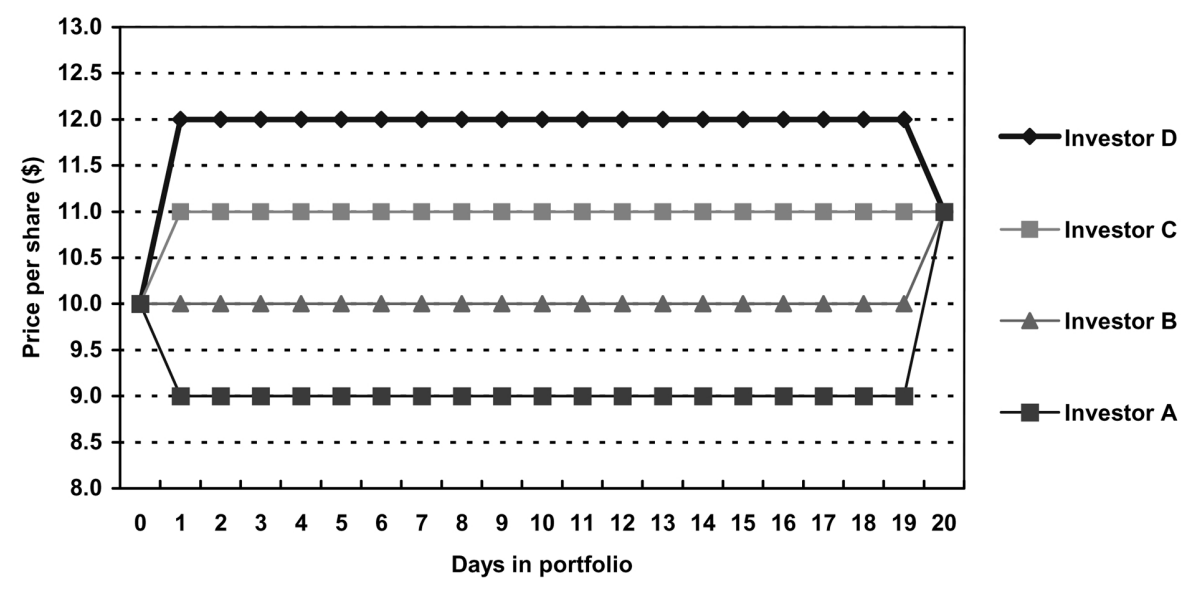

Figure C1 Possible price paths of four investments.

the disposition effect. Our four-stock example shows that considering other stocks in an individual's portfolio does not necessarily help to test for the disposition effect. Assume each investor holds two other stocks. One stock is currently trading for a paper gain while one is trading for a paper loss. If we look at purchase and sale dates only, we come to the conclusion that each investor chooses to sell one of the two potential gains but avoids the one stock currently trading at a loss. Thus, we would conclude that all four investors are equally prone to the disposition effect even though the investors' portfolios had very different histories.

Using data between purchase and sale dates gives additional information. One can argue that Investor A's behavior clearly fits within the framework of loss aversion. Investor A does not sell for the nineteen days when the stock is trading at a loss, but does sell the first day the stock trades at a gain. It is hard to infer how Investor B feels about losses, though we know she sells for a gain at the first opportunity. One can argue that Investor $\mathrm{C}$ is less sensitive to gains than the previous two investors. His stock trades for a gain for nineteen days before he decides to sell on the twentieth day. Finally, it is hard to say much about Investor D and the disposition effect. While she does sell at a gain, she also sells below the stock's high.

We use a stock's trading history (while it is in an investor's portfolio) to estimate the probability the stock is sold for a gain or a loss. For example (and given the data in Figure C), we can say Investor A sells stocks $100 \%$ of the time they trade for a gain while Investor B sells stocks only 5\% of the time they trade for a gain. Likewise, we can say Investor A never sells stocks for a loss even though he had nineteen opportunities to do so. In this particular example, Investors B, C, and D do not help our estimation regarding the propensity to hold losers.

Real data has much more variation thus we can estimate many probabilities: the probability a stock is sold one day after it was bought; the probability a stock is sold 20 days after it was bought; the probability a stock is sold 20 days after it was 
bought conditional on it trading for a gain, etc. Survival analysis provides precisely the machinery needed to use information between a stock's purchase date and sales date.

\section{Appendix D. PGR PLR Analysis}

Odean (1998) tests the hypothesis that the aggregate proportion of gains realized is greater than aggregate proportion of losses realized. He considers each investor's entire portfolio on sales dates (only) by counting each realized gain, realized loss, paper gain, and paper loss as a separate and independent observation. He then aggregates these observations across investors and over time. While these measures may work well for aggregate populations, recent work has attempted to apply the methodology to cross-sectional studies. A typical cross-sectional study calculates the following quantities at the account level:
$N_{r g, i} \quad$ Number of realized gains for investor " $i$ "
$N_{p g, i} \quad$ Number of paper gains for investor " $i$ "
$N_{r l, i} \quad$ Number of realized losses for investor " $i$ "
$N_{p l, i} \quad$ Number of paper losses for investor " $i$ "

The above counts are then used to calculate the proportion of gains realized $\left(P G R_{i}\right)$ and proportion of losses realized $\left(P L R_{i}\right)$ for each investor:

$$
P G R_{i}=\frac{N_{r g, j}}{N_{r g, i}+N_{p g, i}} \quad P L R_{i}=\frac{N_{r l, i}}{N_{r l, i}+N_{p l, i}}
$$

A positive difference $\left(P G R_{i}-P L R_{i}\right)$ is assumed to indicate that investor " $i$ " is prone to the disposition effect. ${ }^{34}$ Current papers that investigate cross-sectional differences in behavior have (typically) tried to regress the difference $\left(P G R_{i}-\right.$ $P L R_{i}$ ) on demographic and trading variables:

$$
P G R_{i}-P L R_{i}=\alpha+\boldsymbol{\beta} \mathbf{X}_{i}+\varepsilon_{i}
$$

Here $\mathbf{X}_{i}$ represents demographic and trading variables for investor " $i$ ". A major problem with the methodology is that the left-hand side variable is linked mathematically to the right-hand side variables.

To better understand this point, we consider four different investors (called "A" "B" "C" and "D".) Each investor holds a set number of stocks in his or her portfolio. We assume that from time to time over the next year, the investors sell stocks. For simplicity, we assume that only one stock is sold on a given day (per investor). Also for simplicity, we assume that every time (day) a stock is sold, a new stock

\footnotetext{
34 Early papers such as Schlarbaum et al. (1978) simply compare the number of realized gains to the number of realized losses. Before Odean's work, a positive difference $\left(N_{r g}-N_{r l}\right)$ was used to indicate the disposition effect.
} 
is immediately purchased. In this way, the number of stocks in each investor's portfolio remains constant. The total number of realized/paper gains/losses per year (for a given investor) is, therefore, equal to the number of stocks in the portfolio times the number of sales dates per year.

We use our four, hypothetical investors to point out problems that occur when performing cross-sectional regressions as shown in Equation (D-i). Problems with PGR and PLR methodology center around the fact that different measures of the disposition effect give different results when used in conjunction with regressions such as (D-i). Some papers use the difference between realized gains and losses as the measure of the disposition effect, some use the difference between PGR and PLR, and some use the ratio of PGR to PLR (minus one). In each case, a value greater than zero could indicate the presences of the disposition effect. Researchers can place any one of the following three measures on the left-hand side of Equation (D-i).

$$
\begin{aligned}
& \text { measure } 1=N_{r g, i}-N_{r l, i} \quad \text { measure } 2=P G R_{i}-P L R_{i} \\
& \text { measure } 3=\frac{P G R_{i}}{P L R_{i}}-1
\end{aligned}
$$

Example \#1. Our first example shows the three measures of the disposition effect can all agree. In panel below, we see that none of the investors appears to be prone

\begin{tabular}{|c|c|c|c|c|c|c|c|c|c|}
\hline Investor & $\begin{array}{c}\text { \# of } \\
\text { Stks. in } \\
\text { Port. }\end{array}$ & $\begin{array}{c}\text { \# of } \\
\text { Sales } \\
\text { per } \\
\text { year }\end{array}$ & $N_{r g, i}$ & $N_{p g, i}$ & $N_{r l, i}$ & $N_{p l, i}$ & $N_{r g, i}-N_{r l, i}$ & $P G R_{i}-P L R_{i}$ & $\frac{P G R_{i}}{P L R_{i}}-1$ \\
\hline $\bar{A}$ & 4 & 12 & 6 & 18 & 6 & 18 & 0.0 & 0.0 & 0.0 \\
\hline B & 8 & 12 & 6 & 42 & 6 & 42 & 0.0 & 0.0 & 0.0 \\
\hline $\mathrm{C}$ & 12 & 12 & 6 & 66 & 6 & 66 & 0.0 & 0.0 & 0.0 \\
\hline D & 16 & 12 & 6 & 90 & 6 & 90 & 0.0 & 0.0 & 0.0 \\
\hline
\end{tabular}
to the disposition effect.

Example \#2. The second example shows the value of Odean's PGR and PLR methodology. While the first measure indicates no disposition effect, the other two measures show that individuals are more likely to sell winners and hold losers.

\begin{tabular}{cccccccccc}
\multicolumn{8}{c}{ \# of } \\
\# of & Sales \\
Stks. in & per & & & & & & \\
Investor & Port. & year & $N_{r g, i}$ & $N_{p g, i}$ & $N_{r l, i}$ & $N_{p l, i}$ & $N_{r g, i}-N_{r l, i}$ & $P G R_{i}-P L R_{i}$ & $\frac{P G R_{i}}{P L R_{i}}-1$ \\
\hline A & 12 & 4 & 2 & 14 & 2 & 30 & 0.0 & 0.06 & 1.0 \\
B & 12 & 8 & 4 & 28 & 4 & 60 & 0.0 & 0.06 & 1.0 \\
C & 12 & 12 & 6 & 42 & 6 & 90 & 0.0 & 0.06 & 1.0 \\
D & 12 & 16 & 8 & 56 & 8 & 120 & 0.0 & 0.06 & 1.0
\end{tabular}


Example \#3. This next example shows that as the number of stocks in the investor's portfolio increases, the difference measure (PGR-PLR) decreases, but the other two measures remain constant. Why is this a problem? If a researcher uses the number of stocks in an investor's portfolio as a proxy for investor sophistication, then the researcher may "find" a link between unsophisticated investors and the disposition effect. However, the researcher will only observe this link (or negative correlation) if the difference measure (PGR-PLR) is used on the left-hand side of Equation (D-i). The other two measures will show no link.

\begin{tabular}{|c|c|c|c|c|c|c|c|c|c|}
\hline Investor & $\begin{array}{c}\# \text { of } \\
\text { Stks. in } \\
\text { Port. }\end{array}$ & $\begin{array}{c}\text { \# of } \\
\text { Sales } \\
\text { per } \\
\text { year }\end{array}$ & $N_{r g, i}$ & $N_{p g, i}$ & $N_{r l, i}$ & $N_{p l, i}$ & $N_{r g, i}-N_{r l, i}$ & $P G R_{i}-P L R_{i}$ & $\frac{P G R_{i}}{P L R_{i}}-1$ \\
\hline A & 4 & 12 & 8 & 16 & 4 & 20 & 4.00 & 0.17 & 1.00 \\
\hline B & 8 & 12 & 8 & 40 & 4 & 44 & 4.00 & 0.08 & 1.00 \\
\hline $\mathrm{C}$ & 12 & 12 & 8 & 64 & 4 & 68 & 4.00 & 0.06 & 1.00 \\
\hline $\mathrm{D}$ & 16 & 12 & 8 & 88 & 4 & 92 & 4.00 & 0.04 & 1.00 \\
\hline
\end{tabular}

Example \#4. Problems can become even more complicated. In this example, as the number of sales per year increases, one measure $\left(N_{r g, i}-N_{r l, i}\right)$ is constant, one measure $\left(\mathrm{PGR}_{i}-\mathrm{PLR}_{i}\right)$ of the disposition effect increases while the third measure $\left(\mathrm{PGR}_{i} / \mathrm{PLR}_{i}-1\right)$ decreases. This is a problem if the researcher uses the number of sales per year as a measure of investor experience. One measure may lead the researcher to believe there is a no correlation, one measure leads to a conclusion of positive correlation, the third measure leads the researcher to believe the correlation is negative.

\begin{tabular}{cccccccccc}
\multicolumn{2}{c}{$\begin{array}{c}\# \text { of } \\
\text { \# of } \\
\text { Stks. in }\end{array}$} & $\begin{array}{c}\text { Sales } \\
\text { per }\end{array}$ & & & & & & & \\
Investor & Port. & year & $N_{r g, i}$ & $N_{p g, i}$ & $N_{r l, i}$ & $N_{p l, i}$ & $N_{r g, i}-N_{r l, i}$ & $P G R_{i}-P L R_{i}$ & $\frac{P G R_{i}}{P L R_{i}}-1$ \\
\hline A & 12 & 4 & 3 & 24 & 1 & 20 & 2.0000 & 0.0635 & 1.3333 \\
B & 12 & 8 & 5 & 36 & 3 & 52 & 2.0000 & 0.0674 & 1.2358 \\
C & 12 & 16 & 9 & 62 & 7 & 114 & 2.0000 & 0.0689 & 1.1911 \\
D & 12 & 24 & 13 & 88 & 11 & 176 & 2.0000 & 0.0699 & 1.1881
\end{tabular}

Other Examples. It is possible to come up with many other examples. In most examples, the three measures of the disposition effect mentioned here give different results. In other words, one measure might lead a researcher to believe that Investor D is more sophisticated than Investor A. However, another measure might lead to the opposite conclusion. For these reasons, and the fact that the conditional probability of a sale is not constant over time, we do not advocate using regressions such as (D-i) to do cross-sectional studies of the disposition effect. 


\section{Appendix E. Trading Losses, Experience, and Alternative Variables}

This table presents hazard ratios associated with an individual's decision to sell/hold stocks. The left-hand side variable takes a value of zero every day the individual holds a stock, and one every day s/he sells a stock. Right-hand side variables vary over time and across individuals. The Trading Loss Indicator (TLI) takes a value of one every day a stock is trading below its purchase price, and zero otherwise. "Experience" measures cumulative number of positions an individual has taken at each point in time. We interact "Experience" with the TLI in order to measure changes in an individual's propensity to hold losers. Other (alternative) variables are displayed at the top of the table. We use a Weibull distribution to parameterize the hazard function. Data are from January 1999 to December 2000 and are provided by a large brokerage house in the People's Republic of China. The table reports robust standard errors that allow for clustering by position (a single position is taken by a single investor in a particular stock-please see text for further details.) The standard errors are shown in parenthesis to the right of the hazard ratios.

\begin{tabular}{|c|c|c|c|c|c|c|}
\hline & \multicolumn{2}{|c|}{ Reg E-i } & \multicolumn{2}{|c|}{ Reg E-ii } & \multicolumn{2}{|c|}{ Reg E-iii } \\
\hline & Ratio & Std. err & Ratio & Std. err & Ratio & Std. err \\
\hline \multicolumn{7}{|l|}{ Alternative Variables } \\
\hline Position Current Gain (Loss) & 5.1404 & $(0.716)$ & & & & \\
\hline Frequency & \multicolumn{6}{|c|}{ Weekly Data } \\
\hline Time Trend & & & & & 1.0015 & $(0.0001)$ \\
\hline \multicolumn{7}{|l|}{ Disposition Effect Variables } \\
\hline Experience $\in[1 \mathrm{st}, 5 \mathrm{th}] \times \mathrm{TLI}$ & 0.5955 & $(0.051)$ & 0.4353 & $(0.033)$ & 0.4533 & $(0.037)$ \\
\hline Experience $\in[6$ th, 10 th $] \times$ TLI & 0.6101 & $(0.056)$ & 0.4793 & $(0.038)$ & 0.4829 & $(0.042)$ \\
\hline Experience $\in[11$ th, 15 th $] \times$ TLI & 0.6640 & $(0.063)$ & 0.5248 & $(0.044)$ & 0.5305 & $(0.048)$ \\
\hline Experience $\in[16 \mathrm{th}, 20 \mathrm{th}] \times \mathrm{TLI}$ & 0.6960 & $(0.071)$ & 0.5480 & $(0.050)$ & 0.5490 & $(0.055)$ \\
\hline Experience $\in[21 \mathrm{st}, 25 \mathrm{th}] \times \mathrm{TLI}$ & 0.6859 & $(0.074)$ & 0.5467 & $(0.053)$ & 0.5655 & $(0.059)$ \\
\hline Experience $\in[26 \mathrm{th}, 30 \mathrm{th}] \times \mathrm{TLI}$ & 0.8099 & $(0.094)$ & 0.6317 & $(0.064)$ & 0.6674 & $(0.074)$ \\
\hline Experience $\in[31 \mathrm{st}, 35 \mathrm{th}] \times \mathrm{TLI}$ & 0.7556 & $(0.091)$ & 0.6004 & $(0.062)$ & 0.6528 & $(0.074)$ \\
\hline Experience $\in[36$ th, 40 th $] \times$ TLI & 0.7936 & $(0.097)$ & 0.6895 & $(0.075)$ & 0.6829 & $(0.084)$ \\
\hline Experience $\in 41$ st $\times$ TLI & 0.8691 & $(0.082)$ & 0.7285 & $(0.061)$ & 0.7451 & $(0.069)$ \\
\hline Number of Trading Rights $\times$ TLI & 1.0314 & $(0.013)$ & 1.0346 & $(0.012)$ & 1.0390 & $(0.013)$ \\
\hline Diversification Dummy $\times$ TLI & 1.1697 & $(0.046)$ & 1.1000 & $(0.038)$ & 1.1551 & $(0.044)$ \\
\hline Gender $(0=\mathrm{F}, 1=\mathrm{M}) \times \mathrm{TLI}$ & 1.3057 & $(0.044)$ & 1.3023 & $(0.041)$ & 1.2932 & $(0.042)$ \\
\hline Age $\in(25,35] \times$ TLI & 1.0788 & $(0.052)$ & 1.0327 & $(0.046)$ & 1.0565 & $(0.050)$ \\
\hline Age $\in(35,45] \times$ TLI & 0.8024 & $(0.045)$ & 0.7995 & $(0.041)$ & 0.7932 & $(0.044)$ \\
\hline Age $\in(45,55] \times$ TLI & 0.8443 & $(0.055)$ & 0.8053 & $(0.050)$ & 0.8399 & $(0.054)$ \\
\hline Age $>55 \times$ TLI & 0.8676 & $(0.060)$ & 0.8500 & $(0.058)$ & 0.8319 & $(0.057)$ \\
\hline \multicolumn{7}{|l|}{ Control variables } \\
\hline Experience $\in$ [1st, 5th] & 1.2388 & $(0.038)$ & 1.1554 & $(0.029)$ & 1.1900 & $(0.031)$ \\
\hline Experience $\in[6$ th, 10th $]$ & 1.2755 & $(0.042)$ & 1.1607 & $(0.032)$ & 1.2182 & $(0.036)$ \\
\hline Experience $\in[11$ th, 15 th $]$ & 1.3873 & $(0.058)$ & 1.2580 & $(0.039)$ & 1.3270 & $(0.046)$ \\
\hline Experience $\in[16$ th, 20th $]$ & 1.5794 & $(0.073)$ & 1.3235 & $(0.048)$ & 1.5097 & $(0.060)$ \\
\hline Experience $\in$ [21st, 25th] & 1.5921 & $(0.086)$ & 1.4188 & $(0.060)$ & 1.5292 & $(0.071)$ \\
\hline Experience $\in$ [26th, 30th] & 1.7186 & $(0.098)$ & 1.5232 & $(0.070)$ & 1.6127 & $(0.087)$ \\
\hline Experience $\in$ [31st, 35th] & 1.8452 & $(0.094)$ & 1.4846 & $(0.067)$ & 1.6876 & $(0.086)$ \\
\hline Experience $\in[36 \mathrm{th}, 40 \mathrm{th}]$ & 2.5502 & $(0.079)$ & 1.8363 & $(0.048)$ & 2.3372 & $(0.067)$ \\
\hline Return $[\mathrm{t}-1, \mathrm{t}-5]$ & 17.1972 & $(1.590)$ & 16.2414 & $(1.086)$ & 37.0164 & $(2.284)$ \\
\hline Return [t-6, t-10] & 2.4826 & $(0.226)$ & 3.0801 & $(0.222)$ & 4.2892 & $(0.363)$ \\
\hline Return [t-11, t-15] & 1.7566 & $(0.154)$ & 2.1556 & $(0.164)$ & 2.6270 & $(0.231)$ \\
\hline Return [t-16, t-20] & 1.0813 & $(0.020)$ & 1.5718 & $(0.114)$ & 1.1085 & $(0.021)$ \\
\hline + Demographic Controls & \multicolumn{2}{|c|}{ Yes } & \multicolumn{2}{|c|}{ Yes } & \multicolumn{2}{|c|}{ Yes } \\
\hline Parameters & & & & & & \\
\hline$p$-parameter & 0.8297 & $(0.004)$ & 0.8863 & $(0.004)$ & 0.8506 & $(0.004)$ \\
\hline
\end{tabular}


Appendix E (continued)

\begin{tabular}{|c|c|c|c|c|c|c|}
\hline & \multicolumn{2}{|c|}{ Reg E-iv } & \multicolumn{2}{|c|}{ Reg E-v } & \multicolumn{2}{|c|}{ Reg E-vi } \\
\hline & Ratio & Std. err & Ratio & Std. err & Ratio & Std. err \\
\hline \multicolumn{7}{|l|}{ Alternative Variables } \\
\hline Month Dum. $\times$ TLI & \multicolumn{2}{|c|}{ Yes } & & & & \\
\hline $\ln \left(\right.$ Port Value $\left._{t}\right) \times$ TLI & & & 1.0432 & $(0.014)$ & & \\
\hline Heterogeneity Control & & & & & \multicolumn{2}{|c|}{ Yes } \\
\hline \multicolumn{7}{|l|}{ Disposition Effect Variables } \\
\hline Experience $\in[1 \mathrm{st}, 5 \mathrm{th}] \times \mathrm{TLI}$ & 0.5146 & $(0.046)$ & 0.3036 & $(0.045)$ & 0.4236 & $(0.037)$ \\
\hline Experience $\in[6$ th, 10 th $] \times$ TLI & 0.5423 & $(0.012)$ & 0.3015 & $(0.047)$ & 0.4683 & $(0.044)$ \\
\hline Experience $\in[11$ th, 15 th $] \times$ TLI & 0.6019 & $(0.059)$ & 0.3234 & $(0.052)$ & 0.5337 & $(0.053)$ \\
\hline Experience $\in[16 \mathrm{th}, 20 \mathrm{th}] \times \mathrm{TLI}$ & 0.6364 & $(0.068)$ & 0.3414 & $(0.057)$ & 0.5519 & $(0.058)$ \\
\hline Experience $\in[21 \mathrm{st}, 25 \mathrm{th}] \times \mathrm{TLI}$ & 0.6485 & $(0.072)$ & 0.3397 & $(0.058)$ & 0.5674 & $(0.064)$ \\
\hline Experience $\in[26 \mathrm{th}, 30 \mathrm{th}] \times \mathrm{TLI}$ & 0.7470 & $(0.088)$ & 0.3965 & $(0.069)$ & 0.6823 & $(0.081)$ \\
\hline Experience $\in[31 \mathrm{st}, 35 \mathrm{th}] \times \mathrm{TLI}$ & 0.7540 & $(0.090)$ & 0.4149 & $(0.073)$ & 0.6645 & $(0.083)$ \\
\hline Experience $\in[36 \mathrm{th}, 40 \mathrm{th}] \times \mathrm{TLI}$ & 0.7793 & $(0.099)$ & 0.3881 & $(0.073)$ & 0.7410 & $(0.099)$ \\
\hline Experience $\in 41$ st $\times$ TLI & 0.8470 & $(0.085)$ & 0.4795 & $(0.077)$ & 0.8090 & $(0.081)$ \\
\hline Number of Trading Rights $\times$ TLI & 1.0333 & $(0.013)$ & 1.0357 & $(0.015)$ & 1.0433 & $(0.014)$ \\
\hline Diversification Dummy $\times$ TLI & 1.1306 & $(0.043)$ & 1.1667 & $(0.050)$ & 1.1556 & $(0.047)$ \\
\hline Gender $(0=\mathrm{F}, 1=\mathrm{M}) \times \mathrm{TLI}$ & 1.3062 & $(0.043)$ & 1.2743 & $(0.047)$ & 1.3812 & $(0.049)$ \\
\hline Age $\in(25,35] \times$ TLI & 1.0552 & $(0.050)$ & 1.0184 & $(0.056)$ & 1.0502 & $(0.056)$ \\
\hline Age $\in(35,45] \times$ TLI & 0.7729 & $(0.043)$ & 0.7390 & $(0.048)$ & 0.7390 & $(0.046)$ \\
\hline Age $\in(45,55] \times$ TLI & 0.8369 & $(0.053)$ & 0.8033 & $(0.059)$ & 0.7942 & $(0.057)$ \\
\hline Age $>55 \times$ TLI & 0.8467 & $(0.058)$ & 0.7588 & $(0.059)$ & 0.8137 & $(0.062)$ \\
\hline \multicolumn{7}{|l|}{ Control variables } \\
\hline Experience $\in[6$ th, 10 th $]$ & 1.1951 & $(0.032)$ & 1.4203 & $(0.046)$ & 1.3102 & $(0.051)$ \\
\hline Experience $\in[11$ th, 15 th $]$ & 1.2189 & $(0.037)$ & 1.5422 & $(0.055)$ & 1.3497 & $(0.060)$ \\
\hline Experience $\in[16 \mathrm{th}, 20 \mathrm{th}]$ & 1.3406 & $(0.047)$ & 1.6987 & $(0.068)$ & 1.5624 & $(0.079)$ \\
\hline Experience $\in$ [21st, 25th] & 1.5013 & $(0.060)$ & 2.0026 & $(0.090)$ & 1.8892 & $(0.111)$ \\
\hline Experience $\in[26 \mathrm{th}, 30 \mathrm{th}]$ & 1.5513 & $(0.072)$ & 2.0863 & $(0.107)$ & 2.0149 & $(0.134)$ \\
\hline Experience $\in[31 \mathrm{st}, 35 \mathrm{th}]$ & 1.6194 & $(0.088)$ & 2.1927 & $(0.135)$ & 2.1606 & $(0.159)$ \\
\hline Experience $\in$ [36th, 40th $]$ & 1.7119 & $(0.088)$ & 2.3847 & $(0.135)$ & 2.2416 & $(0.183)$ \\
\hline Experience $\in 41$ st & 2.3824 & $(0.068)$ & 3.2373 & $(0.109)$ & 3.7800 & $(0.162)$ \\
\hline Return $[\mathrm{t}-1, \mathrm{t}-5]$ & 26.9177 & $(2.133)$ & 33.5697 & $(2.835)$ & 82.7998 & (7.979) \\
\hline Return [t-6, t-10] & 3.1177 & $(0.267)$ & 4.0318 & $(0.381)$ & 8.9614 & $(0.924)$ \\
\hline Return $[\mathrm{t}-11, \mathrm{t}-15]$ & 1.9345 & $(0.166)$ & 2.5012 & $(0.244)$ & 3.8504 & $(0.395)$ \\
\hline Return $[\mathrm{t}-16, \mathrm{t}-20]$ & 1.0872 & $(0.020)$ & 1.1042 & $(0.022)$ & 1.0994 & $(0.029)$ \\
\hline + Demographic Controls & \multicolumn{2}{|c|}{ Yes } & \multicolumn{2}{|c|}{ Yes } & \multicolumn{2}{|c|}{ Yes } \\
\hline \multicolumn{7}{|l|}{ Parameters } \\
\hline$p$-parameter & 0.8728 & $(0.004)$ & 0.8690 & $(0.005)$ & 1.3084 & $(0.012)$ \\
\hline
\end{tabular}




\section{References}

Ang, A. and Maddaloni, A. (2005) Do demographic changes affect risk premiums? Evidence from international data, Journal of Business 78(1), 341-379.

Barber, B. and Odean, T. (2001) Boys will be Boys: gender, overconfidence, and common stock investment, Quarterly Journal of Economics 116(1), 261-292.

Brown, P., Chappel, N., da Silva Rosa, R., and Walter, T. (2003) The reach of the disposition effect: Large sample evidence across investor classes, unpublished working paper, University of Western Australia.

Chen, G., Kim, K., Nofsinger, J., and Rui, O. (2004) Behavior and performance of emerging market investors: Evidence from China, unpublished working paper, Washington State University.

Coval, J. and Shumway, T. (2004) Do behavioral biases affect rices? Journal of Finance 60(1), 1-34.

Dhar, R. and Zhu, N. (2005) Up close and personal: An individual level analysis of the disposition effect, unpublished working paper, Yale University.

Ferris, S., Haugen, R., and Makhija, A. (1988) Predicting contemporary volume with historic volume at differential price levels: Evidence supporting the disposition effect, Journal of Finance 43, 677-699.

Frazzini, A. (2004) The disposition effect and under-reaction to news, unpublished working paper, Yale University.

Garvey, R. and Murphy, A. (2004) Are professional traders too slow to realize their losses?, Financial Analyst Journal 60(4), 35-43.

Genesove, D. and Mayer, C. (2001) Loss aversion and seller behavior: Evidence from the housing market, Quarterly Journal of Economics 116(4), 1233-1260.

Goyal, A. (2004) Demographics, stock market flows, and stock returns, Journal of Financial and Qualitative Analysis 39(1), 115-142.

Grinblatt, M. and Keloharju, M. (2001) What makes investor trade?, Journal of Finance 56(2), 589616.

Haigh, M. and List J. (2005) Do professional traders exhibit myopic loss aversion? An experimental analysis, Journal of Finance 60(1), 523-534.

Heisler, J. (1994) Loss aversion in a futures market: An empirical test, Review of Futures Markets 13(3), 793-826.

Ivkovic, Z., Poterba, J., and Weisbenner, S. (2004) Tax-motivated trading by individual investors, NBER working paper 10275.

Jenkins, S. (2004) Class notes on survival analysis with stata, University of Essex. Can be found at http://www.iser.essex.ac.uk/teaching /stephenj /ec968/

Kahneman, D. and Tversky, A. (1979) Prospect theory: An analysis of decision under risk, Econometrica 47(2), 263-292.

Kumar, A. and Lim, S. (2004) One trade at a time: Narrow framing and stock investment decisions of individual investors, unpublished working paper, University of Notre Dame.

Lakonishok, J. and Smidt, S. (1986) Volume for winners and losers: Taxation and other motives for stock trading, Journal of Finance 41, 951-974.

Lim, S. (2004) Do investors integrate losses and segregate gains? Mental accounting and investor trading decisions, unpublished working paper, DePaul University.

List, J. (2003) Does market experience eliminate market anomalies?, Quarterly Journal of Economics 118(1), 41-71.

Locke, P. and Mann, S. (2003) Prior outcomes and risk choices by professional traders, unpublished working paper, George Washington University.

Locke, P. and Mann, S. (2005) Professional trade discipline and trade disposition, Journal of Financial Economics 76(3), 401-444.

Locke, P. and Onayev, Z. (2005) Trade duration: Information and Trade Disposition, The Financial Review 40(1). 
O'Connell, P. and Teo, M. (2003) Prospect theory and institutional investors, unpublished working paper, FDO Partners LLC.

Odean, T. (1998) Are investors reluctant to realize their losses?, Journal of Finance 53(5), 17751798.

Schlarbaum, G., Lewellen W., and Lease, R. (1978) Realized returns on common stock investments: The experience of individual investors, Journal of Business 51, 299-325.

Shapira, Z. and Venezia, I. (2001) Patterns of behavior of professionally managed and independent investors, Journal of Banking and Finance 25(8), 1573-1587.

Shefrin, H. and Statman, M. (1985) The disposition to sell winners too early and ride losers too long: Theory and evidence, Journal of Finance 40(3), 777-790.

STATA (2003) Survival Analysis and Epidemiological Tables, STATA Press, College Station, TX.

Vissing-Jorgensen, A. (2003) Perspective on behavioral finance: Does irrationality disappear with wealth? Evidence from expectations and actions, NBER Macroeconomics Annual.

Weber, M. and Camerer, C. (1998) The disposition effect in securities trading: An experimental analysis, Journal of Economic Behavior and Organization 33, 167-184. 
